\title{
Coble, Orowan Strengthening, and Dislocation Climb Mechanisms in a Nb-Modified Zircaloy Cladding
}

\author{
BOOPATHY KOMBAIAH and KORUKONDA LINGA MURTY
}

\begin{abstract}
Biaxial creep tests on HANA-4 tubes, Nb-added Zircaloy-4 were conducted using internal pressurization of closed-end tubes to investigate the rate-controlling mechanisms over a range of hoop stresses, $8.38 \times 10^{-5} E-2.87 \times 10^{-3} E$, at three different temperatures $673 \mathrm{~K}, 723 \mathrm{~K}$, and $773 \mathrm{~K}\left(400{ }^{\circ} \mathrm{C}, 450{ }^{\circ} \mathrm{C}\right.$, and $\left.500{ }^{\circ} \mathrm{C}\right)$. The mechanistic creep parameters such as stress exponent $(n)$ and activation energy $\left(Q_{\mathrm{C}}\right)$ were then determined from steady-state creep rates. Based on the variance in stress exponent with respect to the applied stress, three regimes have been identified: a stress exponent close to 1 at low stresses that increased to 3 at the intermediate stresses, which became 4.5 at high stresses. An activation energy value of $226 \mathrm{~kJ} / \mathrm{mol}$ was evaluated for the $n=3$ and $n=4.5$ regimes, which lies close to the activation energy for self-diffusion $\left(Q_{\mathrm{L}}\right)$ in $\alpha-\mathrm{Zr}$ alloys. Further, TEM analyses of crept microstructures and comparison of experimental results with standard models were undertaken to find out the rate-controlling mechanisms. Coble creep, climbing of dislocations to bypass $\beta$ - $\mathrm{Nb}$ precipitates, and dynamic recovery by edge dislocation climb are proposed as the rate-controlling mechanisms in the $n=1, n=3$, and $n=4.5$ regimes of HANA- 4 , respectively.
\end{abstract}

DOI: $10.1007 / \mathrm{s} 11661-015-3060-8$

(C) The Minerals, Metals \& Materials Society and ASM International 2015

\section{INTRODUCTION}

ZIRCONIUM alloys have found extensive applications in nuclear reactors as fuel rods and structural materials for several decades owing to their attractive properties such as sufficient mechanical strength at high temperatures, good corrosion resistance, and more importantly, low absorption cross section for thermal neutrons. In particular, Zircaloy-2 and Zircaloy-4 with major alloying elements of $\mathrm{Sn}, \mathrm{Fe}$, and $\mathrm{Cr}$ have been serving boiling water reactors (BWR) and pressurized water reactors (PWR), respectively, for several decades. ${ }^{[1]}$ However, with the advent of using these cladding materials for extended burn-up as well as Generation-IV reactor design concepts, the materials inside the reactors are expected to function reliably at higher temperatures, higher neutron doses, and extremely corrosive environment for far longer times. ${ }^{[2]}$ This critically demands for improved microstructural design in reactor structural materials through various methods such as altering composition and processing routes to attain better properties. One such attempt toward realizing this goal was to add Niobium to Zircaloys for achieving an improved long-term corrosion resistance and mechanical properties without losing the neutron absorption

BOOPATHY KOMBAIAH, PhD Student, is with the Department of Materials Science and Engineering, North Carolina State University, Raleigh, NC 27695. Contact e-mail: bkombaiah@gmail.com KORUKONDA LINGA MURTY, Professor, is with the Department of Materials Science and Engineering, North Carolina State University, and also with the Department of Nuclear Engineering, North Carolina State University.

Manuscript submitted April 15, 2015.

Article published online July 18, 2015 characteristics, the attributes which are generally ascribed to the distribution of $\beta-\mathrm{Nb}$ precipitates in the microstructure. ${ }^{[3,4]}$ For instance, $\mathrm{Zr}-2.5$ pctNb pressure tubes are currently used in pressurized heavy water reactors (PHWR). As well, Nb-modified $\mathrm{Zr}$ cladding alloys such as Zirlo and M5 have been developed in USA and Europe for applications in modern PWRs. ${ }^{[2]}$ Along this line, the Zircaloy fuel cladding team at Korea Atomic Energy Research Institute (KAERI) has recently developed several $\mathrm{Zr}$-Nb cladding alloys, known as HANA (High performance Alloy for Nuclear Applications) alloys, with optimum composition and processing conditions to enhance their structural properties. ${ }^{[5-8]}$ The out-of-pile and in-pile performance evaluations of these alloys demonstrated their improved corrosion resistance as well as mechanical properties than Zircaloy-4 probably due to the effect of finely distributed second-phase precipitates in HANA claddings. ${ }^{[9]}$

Among several possible performance degradation phenomena occurring in nuclear fuel cladding materials such as creep, stress-corrosion cracking, and delayed hydrogen cracking, creep is regarded as the prime degradation mechanism. Further, knowledge on transitions in creep mechanisms becomes essential not only in predicting the life times of fuel claddings conservatively but also can be useful in designing microstructures with better creep resistance. ${ }^{[10,11]}$ To this end, several investigations were undertaken to comprehend the creep behavior of $\mathrm{Zr}-\mathrm{Nb}$ alloys which were recently reviewed by Charit and Murty for different $\mathrm{Zr}-\mathrm{Nb}$ based alloys with an emphasis on the transitions in creep mechanisms over a range of stress and temperature conditions. ${ }^{[3,12-17]}$ From the review, a common trend that can be noted in all the $\mathrm{Zr}-\mathrm{Nb}$ based alloys considered vis-à-vis the change in stress exponent $(n)$ as a function of the applied 
stress is as following: $n=1$ at low stresses changes to $n=3$ at intermediate stresses, which then transits into a $n=5$ to 7 regime at high stresses. Based on the analyses of the stress exponent values in combination with the creep activation energies in the three regimes, the ratecontrolling mechanisms for the creep deformation have been proposed. For instance, Coble creep, which is a Newtonian viscous flow mechanism, was attested to the $n=1$ regime at low stresses for $\mathrm{Zr}-\mathrm{Nb}$ alloys with fine grain size, lesser than $<10 \mu \mathrm{m}$. In the intermediate regime that behaves like the natural power law creep with $n=3$, viscous glide mechanism mediated by dragging of dislocations by niobium solutes has been suggested as the rate-controlling process while climb of edge dislocations at high stresses. However, TEM analyses of the deformation microstructures in support of the viscous dragging mechanism were undertaken by only a very few studies. For example, Murty et al. showed dislocations uniformly distributed throughout the zirconium matrix without forming into sub-boundary or networks, possibly indicating viscous glide mechanism to be operative in the $n=3$ regime. ${ }^{[8,19]}$ However, at the temperatures of interest, $\mathrm{Nb}$ exhibits distinct precipitate formation with very little solid solubility in $\mathrm{Zr}$ thereby rendering doubt as to the locking of the dislocations by $\mathrm{Nb}$ solid solutes. As the applied stress becomes larger than a critical stress of about $7.5 \times 10^{-4} E$, which is sufficient to break away the dislocations bounded by the niobium solutes, ${ }^{[20]}$ the creep deformation of $\mathrm{Zr}-\mathrm{Nb}$ alloys was postulated to be controlled by dislocation climb, which is now the slower process between glide and climb acting sequentially. In this regime, the crept microstructures revealing subgrains bounded by dislocations ${ }^{[16]}$ and dislocation networks $^{[3]}$ in TEM micrographs were ascribed to the occurrence of dislocation climb-controlled process. In addition, the activation energies determined for $n=3$ and $n=5$ to 7 regimes were found to be close to the lattice self-diffusion activation energy in $\alpha-\mathrm{Zr}$, since both glide and climb are controlled by solute atom diffusion and self-diffusion that are noted to have similar activation energies. Based on these observations, it can be argued that $\mathrm{Zr}-\mathrm{Nb}$ alloys behave like a class-A alloy during creep at intermediate stresses, whereas they act as a class-M alloy at high stresses similar to $\alpha$-zirconium and its alloys with tin as major alloying element such as Zircaloy-2 and Zircaloy-4. ${ }^{[21,22]}$

Though there exists a consistency in the mechanistic creep parameters like stress exponent and activation energy at a range of stresses in several $\mathrm{Zr}-\mathrm{Nb}$ alloys, more detailed analyses of the deformation microstructure are warranted to unambiguously detect the ratecontrolling mechanisms. With this in mind, the creep behavior of HANA-4 (Zr-1.5 pctNb alloy) cladding, which is a potential candidate for nuclear fuel claddings, has been investigated with a focus on identifying the transitions in creep mechanisms along with emphasis on deformation microstructures. Biaxial creep tests on HANA-4 tubes were conducted using internal pressurization of closed-end tubes, which simulates similar loading conditions experienced by fuel claddings in reactors, to gather the steady-state creep data over a range of stress and temperature conditions. From the analysis, the creep data of HANA-4 were noted to follow a similar trend observed in other $\mathrm{Zr}-\mathrm{Nb}$ alloys with respect to the variance of stress exponent as a function of stress ( $n=1, n=3$, and $n=4.5$, respectively, at low, intermediate, and high stresses) as well as the activation energies being equivalent to that for the lattice self-diffusion in $\alpha-\mathrm{Zr}$ in the $n=3$ and $n=4.5$ regimes. However, it is postulated from the analyses of the deformation microstructures using TEM that dislocations bypassing the $\beta$-Nb precipitates in HANA-4 through the climb process are the rate-controlling mechanism, as against the usually perceived viscous glide mechanism, in the $n=3$ regime. Furthermore, the recovery of dislocations by climb, as suggested by the pillbox model from Weertman, is proposed as the dominant mechanism in the $n=4.5$ regime. ${ }^{[23]}$ The stress at the point of transition from the $n=3$ regime to the $n=4.5$ regime has been identified as the critical stress required by dislocations to bypass the precipitates in HANA-4 via the well-known Orowan mechanism. ${ }^{[24,25]}$ For the first time, we show that the creep behavior of a $\mathrm{Zr}-\mathrm{Nb}$ alloy is similar to that of certain precipitation-hardened materials, but not of a class-A alloy.

\section{MATERIALS AND EXPERIMENTS}

HANA 4 tubes with an outer diameter $\left(D_{\mathrm{o}}\right)$ of $9.50 \mathrm{~mm}$ and a wall thickness $(t)$ of $0.57 \mathrm{~mm}$ were received from KAERI in cold-worked and stress-relieved condition. The chemical composition of the tubing is given in Table I. The as-received tubes were annealed at $810 \mathrm{~K}\left(537^{\circ} \mathrm{C}\right)$ for 4 hours inside a vacuum furnace continuously purged with argon gas to reduce their oxidation. The annealing temperature was chosen so that the creep tests with temperature as high as $773 \mathrm{~K}\left(500{ }^{\circ} \mathrm{C}\right)$ in this study could be carried out with little microstructural changes. With an outer diameter to wall thickness ratio of lesser than 0.1 , the thin-wall approximation, i.e., radial stress is negligible, can be applied to the HANA tubing. Biaxial creep testes were then carried out vis-à-vis closed-end internal pressurization of the tubes which gives rise to a stress ratio (i.e., hoop stress to axial stress) of $2: 1$. The hoop $\left(\sigma_{\theta}\right)$ and axial stresses $\left(\sigma_{\mathrm{Z}}\right)$ were calculated using the relations,

$$
\sigma_{\theta}=\frac{p D_{\mathrm{m}}}{2 t},
$$

Table I. Chemical Composition of HANA-4 Tested in This Study

\begin{tabular}{ll}
\hline Element & Amount \\
\hline Niobium & $1.5 \mathrm{pct}$ \\
Tin & $0.4 \mathrm{pct}$ \\
Iron & $0.2 \mathrm{pct}$ \\
Chromium & $0.1 \mathrm{pct}$ \\
Oxygen & $1100 \mathrm{ppm}$ \\
Silicon & $100 \mathrm{ppm}$ \\
Zirconium & rest \\
\hline
\end{tabular}




$$
\sigma_{\mathrm{Z}}=\frac{p D_{\mathrm{m}}}{4 t}
$$

where $D_{\mathrm{m}}$ is the mean tube diameter and $p$ is the argon pressure inside tube. Biaxial creep testing of HANA-4 tubing was carried out by applying a range of hoop stresses, $8.38 \times 10^{-5} \mathrm{E}$ to $2.87 \times 10^{-3} \mathrm{E}$, at temperatures, $673 \mathrm{~K}, 723 \mathrm{~K}$, and $773 \mathrm{~K}\left(400{ }^{\circ} \mathrm{C}, 450{ }^{\circ} \mathrm{C}\right.$, and $500{ }^{\circ} \mathrm{C}$ ). The biaxial creep specimens were prepared by closing the ends of the tubes with Swagelok fittings except for an inlet to internally pressurize with argon gas as shown in Figure 1(a). A gas pressurization system comprising a gas booster and an air compressor capable of generating up to 17,000 psi of argon pressure was utilized as a source to supply the pressure to attain the required hoop stresses (Figure 1(b)). Before each creep test, it was ensured that the specimen could hold up the set pressure without any gas leakage. The test temperatures were attained by heating the specimen using a one-zone furnace that was connected to an $\operatorname{ATS}^{\circledR}$ temperature controller. Two K-type thermocouple wires were wound on the specimen in order to measure and control the temperature accurately within a range of $\pm 3 \mathrm{~K}$. The diametrical expansion $\left(\Delta D_{\mathrm{o}}\right)$ of the tubing during creep test was in situ measured by a non-contact Beta lasermike (Figure 1(c)) with an accuracy of as low as $2.5 \mu \mathrm{m}$ and was continuously logged by a computer. The hoop strain $(\varepsilon)$ was then measured using the relation,

$$
\varepsilon=\frac{\Delta D}{D_{0}}
$$

Since the axial strain produced in tube specimen under the biaxial loading with 2:1 stress ratio is negligible, only the hoop strain was measured for further analysis. ${ }^{[26]}$ Once the steady-state creep rates were achieved, the creep tests were stopped by cooling the specimen down to room temperature using forced air-flow under loaded condition in order to preserve the deformation microstructures.

Since the tube specimens were heated in the atmospheric air without any protection for oxidation during the creep tests, any thickness variation originated from the oxide scale formation could be added up to the creep-induced diametrical expansion by the lasermike resulting in a wrong interpretation of the data. However, it was noted from oxidation experiments, in which HANA 4 tubing was heated in the atmospheric air without the application of pressure that the thickness increment arising solely from the oxide scale formation is negligible for the test temperatures employed here. For instance, heating the HANA 4 tubing at $798 \mathrm{~K}\left(525^{\circ} \mathrm{C}\right)$ for 20 days increased its thickness by only about $0.4 \mu \mathrm{m}$ owing to the formation of oxide scale, which is an insignificant $\left(\varepsilon_{\theta} \cong 10^{-5}\right)$ fraction of the diametrical expansion obtained from our creep tests.

The microstructures of the specimens before and after creep were characterized using TEM with an objective to detect the dominant mechanism operative under the testing conditions. To this end, the walls of the tube specimens were sectioned using a low speed saw and polished using 800 fine grit sand-papers down to $\sim 100 \mu \mathrm{m}$ thick flat sheet for synthesizing TEM thin
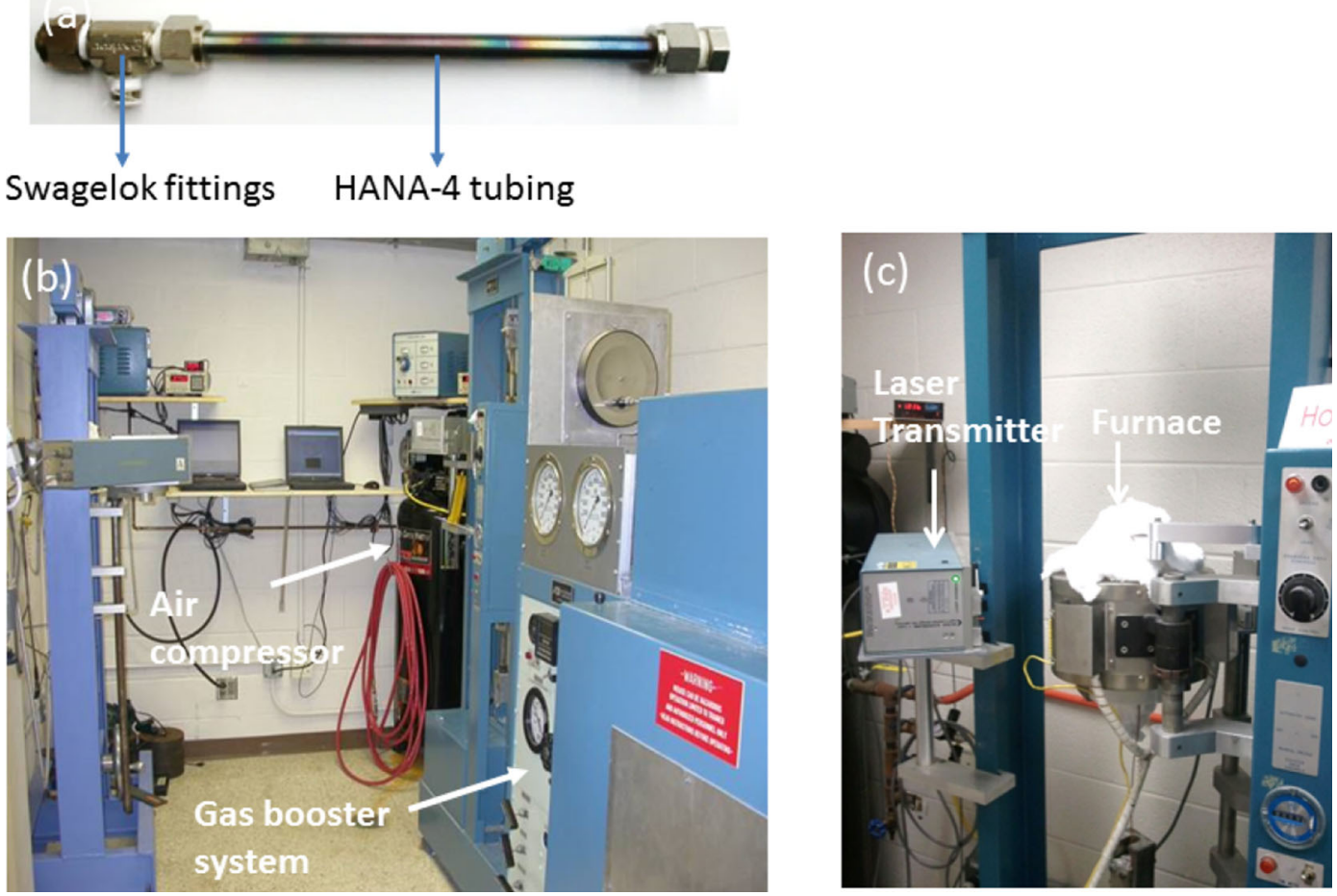

Fig. 1-(a) Biaxial creep specimen of HANA-4 tubing. (b) Air compressor and gas booster system capable of generating 17,000 psi pressure to supply the required pressure for the biaxial creep tests. (c) Biaxial creep set-up showing the lasermike and the furnace. 
specimens. The flat sheets were then punched using a mechanical punch into $3 \mathrm{~mm}$ disks, which were further polished using a model 110 Fischione automated twinjet polisher to produce the final thin specimens at $213 \mathrm{~K}$ $\left(-60{ }^{\circ} \mathrm{C}\right)$ by applying a voltage of $25 \mathrm{~V}$ using the following electrolytic solution: $30 \mathrm{~mL}$ sulfuric acid and $1 \mathrm{~mL}$ hydrofluoric acid in $470 \mathrm{~mL}$ methanol. A $200 \mathrm{keV}$ JEOL 2010F TEM equipped with a double tilt-holder was employed for imaging the microstructures. In addition, compositional analysis of the secondary phases in this alloy was conducted using energy dispersive X-ray spectroscopy (EDS) mapping in a $200 \mathrm{keV}$ aberration-corrected FEI Titan G2 microscope with an $\mathrm{X}$-FEG source and ChemiSTEM technology which was operated under scanning transmission electron microscope (STEM) mode. The EDS maps were recorded over areas of $108 \times 101 \mathrm{~nm}$ in $420 \times 392$ pixels for about 20 minutes.

\section{RESULTS}

\section{A. Microstructure of Annealed HANA-4}

Figure 2(a) presents the inverse pole figure map of the annealed HANA 4 from which grain size distribution (Figure 2(b)) and pole (basal and prism) figures (Figure 3) were evaluated. An average grain size of about $3.6 \pm 2.5 \mu \mathrm{m}$ was determined by fitting the plot of grain size $v s$ area fraction with a Gaussian distribution function. From the pole figures, it can be seen that the annealed HANA 4 possessed a texture which is comparable to the one that was observed in zirconium alloys. ${ }^{[27]}$ The basal poles were noted to be aligned at an angle of about \pm 20 to $40^{\circ}$ from the radial direction toward the hoop direction as seen in Figure 3. On the other hand, the maximum intensity of the prism poles existed at a slightly tilted angle from the axial direction.

TEM micrographs of the annealed HANA-4, given in Figure 4, revealed recrystallized grains with a low density of dislocations without forming any entangles or sub-boundaries. Additionally, second-phase precipitates, most of them in rounded shape, were observed to be distributed throughout grain interiors as well as at grain boundaries. The size of the precipitates of about 500 numbers in different grains was measured from the micrographs using the ImageJ software. The size distribution of precipitates is complied with a log-normal distribution with an average diameter (d) of about $63 \pm 35 \mathrm{~nm}$ as shown in Figure 5. Similarly, the precipitate size distribution in the HANA-4 tubing crept at $723 \mathrm{~K}\left(450^{\circ} \mathrm{C}\right)$ and $50 \mathrm{MPa}$ for 5 days in regime II was determined from the measurements of about 500 precipitates (Figure 5), which also complied to a lognormal distribution with an average precipitate diameter of $57 \pm 34 \mathrm{~nm}$. As seen, no statistically significant change in the precipitate size distribution is determined in the HANA-4 tube after a prolonged heating indicating the presence of stable precipitates. Further, energy dispersive X-ray spectroscopy (EDS) elemental maps of a precipitate surrounded by the matrix are presented in Figure 6. It was quite evident from the maps that the precipitates are composed of niobium as the major element. The quantitative analysis of the elements determined by the software provided the chemical
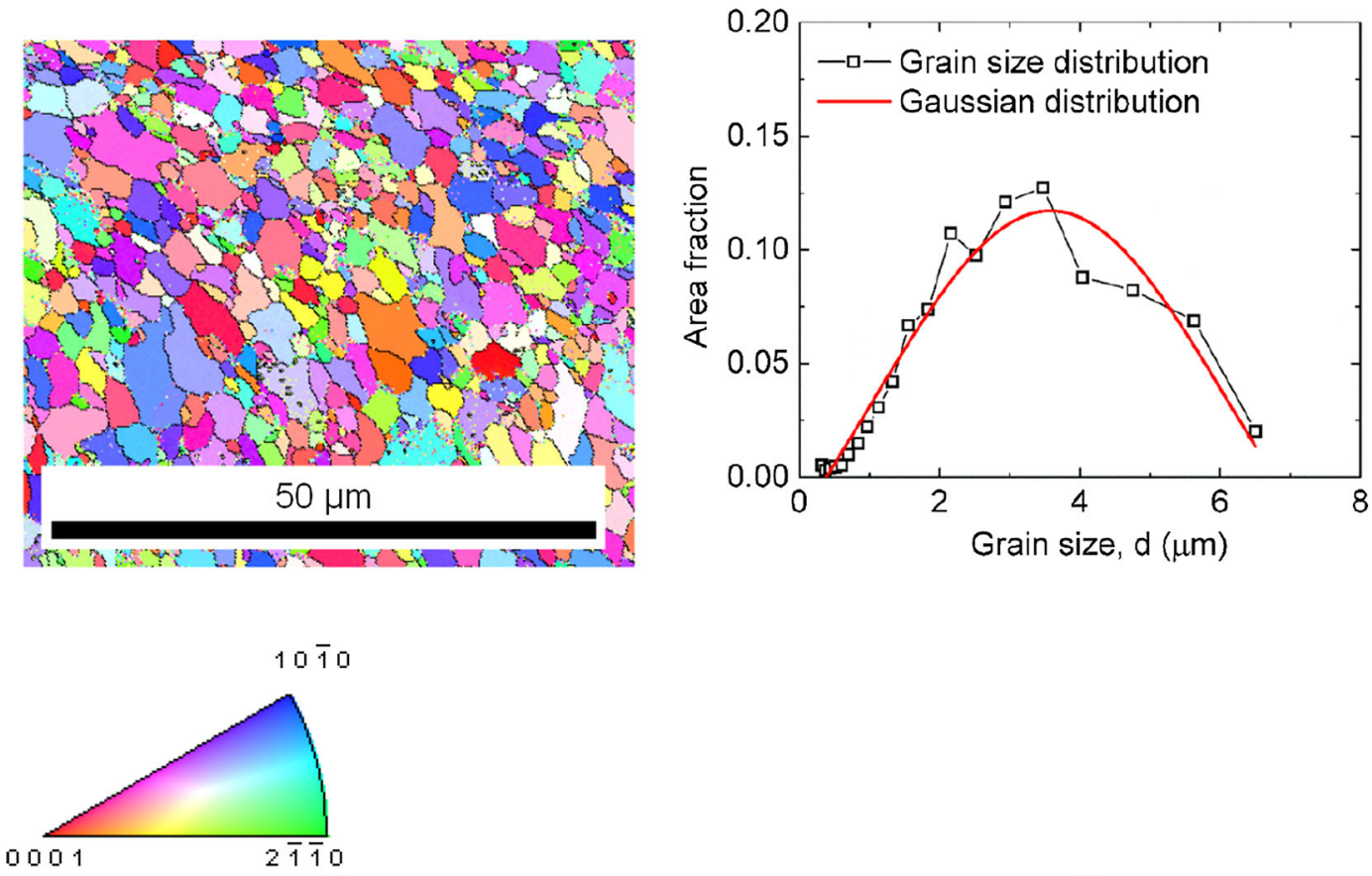

(a)

(b)

Fig. 2 - (a) Inverse pole figure maps depicting the grain orientation in the annealed HANA-4 tubing at $810 \mathrm{~K}\left(537{ }^{\circ} \mathrm{C}\right)$ for $4 \mathrm{~h}$ with the orientation legend placed below, $(b)$ the grain size distribution calculated from the inverse pole figure map revealing an average grain size of about $3.8 \mu \mathrm{m}$. 


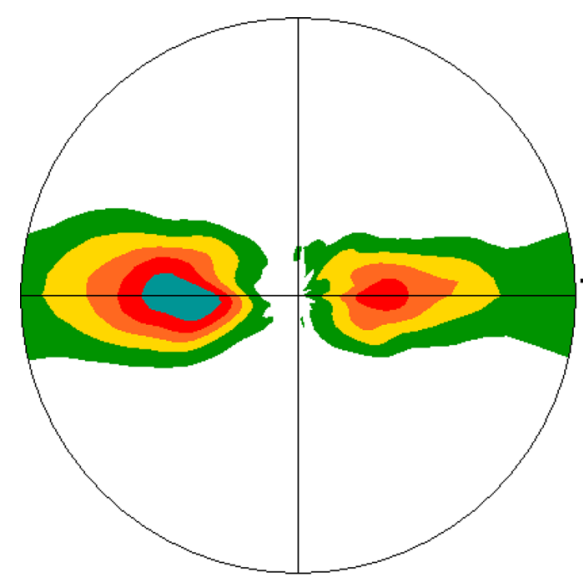

0002

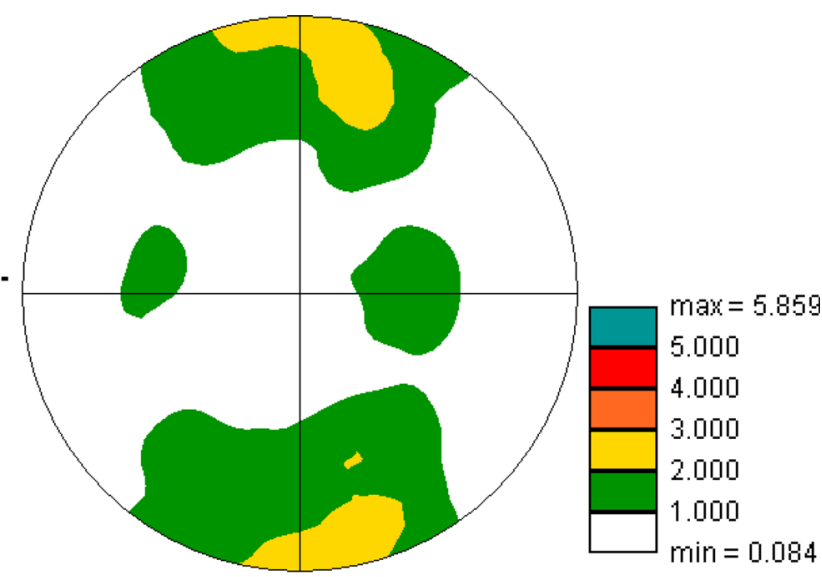

$10 \overline{1} 0$

Fig. 3-Pole figures of (0002) and (1010) with the thickness direction $(r)$ at the center along with axial direction $(z)$ on the top and hoop $(\theta)$ at $90 \mathrm{deg}$ along the horizontal direction of annealed HANA-4 tubing with the legend showing intensity distribution.
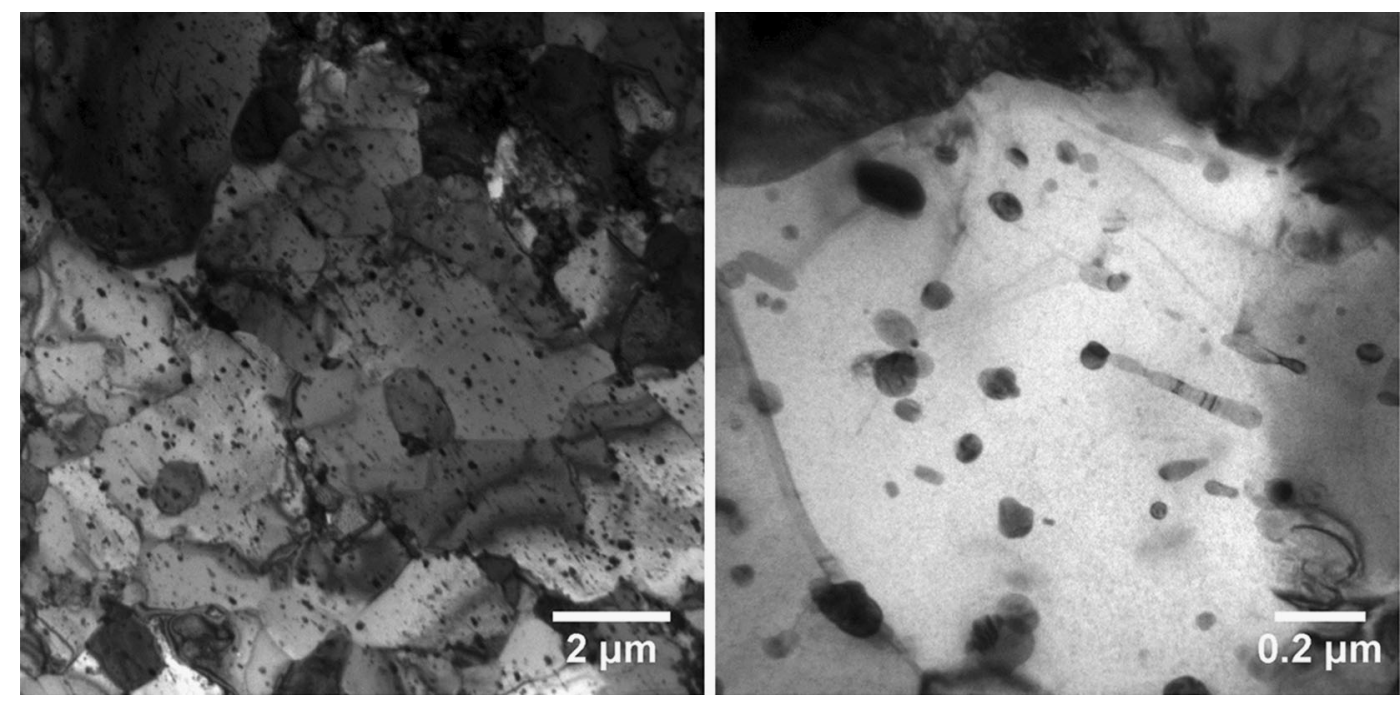

Fig. 4-Representative TEM micrographs of annealed HANA-4 showing recrystallized grains with fine precipitates distributed throughout the matrix.

composition of the precipitates to be $\mathrm{Nb}-82.6 \mathrm{pct}$, Zr-17 pct, Cr-0.2 pct, and Fe-0.2 pct. The diffraction patterns obtained from the precipitates confirm that they have BCC crystal structure as depicted in Figure 7. The preceding analyses indicate that these are $\beta-\mathrm{Nb}$ (BCC) second-phase precipitates, which are generally present in $\mathrm{Zr}-\mathrm{Nb}$ alloys owing to a very low solubility of $\mathrm{Nb}$ in $\mathrm{Zr}$ at room temperature according to the $\mathrm{Zr}-\mathrm{Nb}$ phase diagram (Figure 8). ${ }^{[28-30]}$ As well, similar secondphase precipitates were observed to be present in HANA-6 alloys (Zr-1.1 pctNb), which are processed in a similar way like that of HANA-4. ${ }^{[9]}$

\section{B. Stress Exponent and Activation Energy}

Figure 9 shows a representative creep curve of a specimen deformed at $100 \mathrm{MPa}$ and $723 \mathrm{~K}\left(450^{\circ} \mathrm{C}\right)$. The creep curves in general exhibited the primary creep regime initially, wherein the creep rate showed a decreasing trend with time, and followed by the steady-state creep regime, wherein the creep rate became time invariant. The steadystate creep rates and the total strain along with the stresses and temperatures employed in the tests are given in Table II. The steady-state creep rate data were further analyzed to note the rate-controlling mechanisms at the testing conditions. At the outset, two important creep parameters namely stress exponent $(n)$ and activation energy $\left(Q_{\mathrm{c}}\right)$ were obtained from the general creep equation relating the steady-state creep rate $\left(\dot{\varepsilon}_{\mathrm{s}}\right)$ with the applied stress $(\sigma)$ and temperature ( $T$ in $K$ ) that can be stated as,

$$
\begin{gathered}
\dot{\varepsilon}_{\mathrm{s}}=\frac{A E b}{k T}\left(\frac{\sigma}{E}\right)^{n} \mathrm{e}^{-\frac{Q_{\mathrm{c}}}{R T}}, \\
E=95.92-0.0629(T-273) \mathrm{GPa} .
\end{gathered}
$$


In Eq. [3a], $A$ is a constant, $E$ is the temperaturedependent elastic modulus of $\mathrm{Zr}-2.5 \mathrm{pct} \mathrm{Nb}{ }^{[31]} b$ is the burgers vector $\left(3.23 \times 10^{-10} \mathrm{~m}\right), k$ is the Boltzmann's
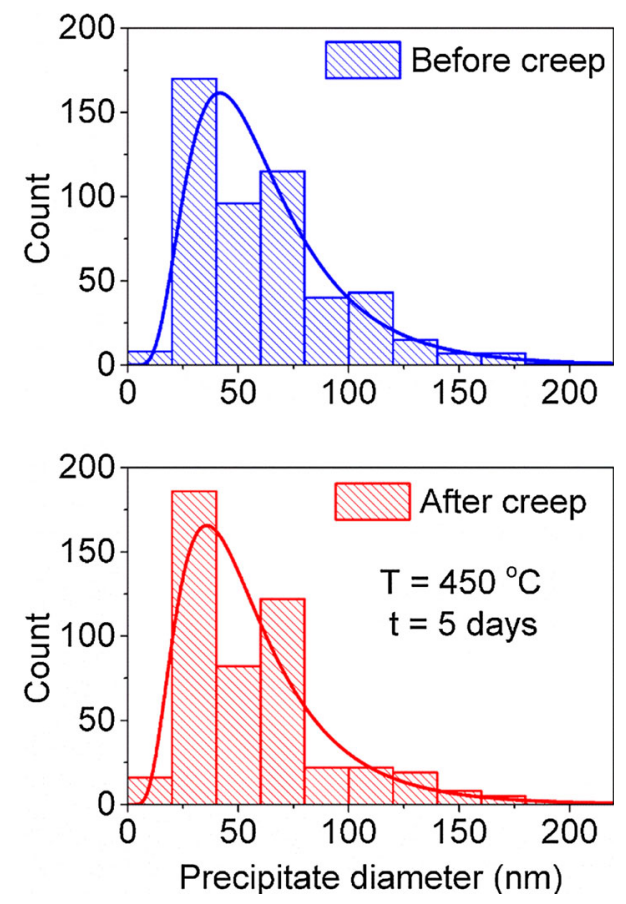

Fig. 5-The size distribution of the precipitates in HANA-4 before creep (top) and after crept at $723 \mathrm{~K}\left(450^{\circ} \mathrm{C}\right)$ for 5 days (bottom). constant, and $R$ is the gas constant. From Eq. [3a], the stress exponent is equivalent to the slope of the $\log -\log$ plot between the steady-state creep rate $v s$ the modulus-

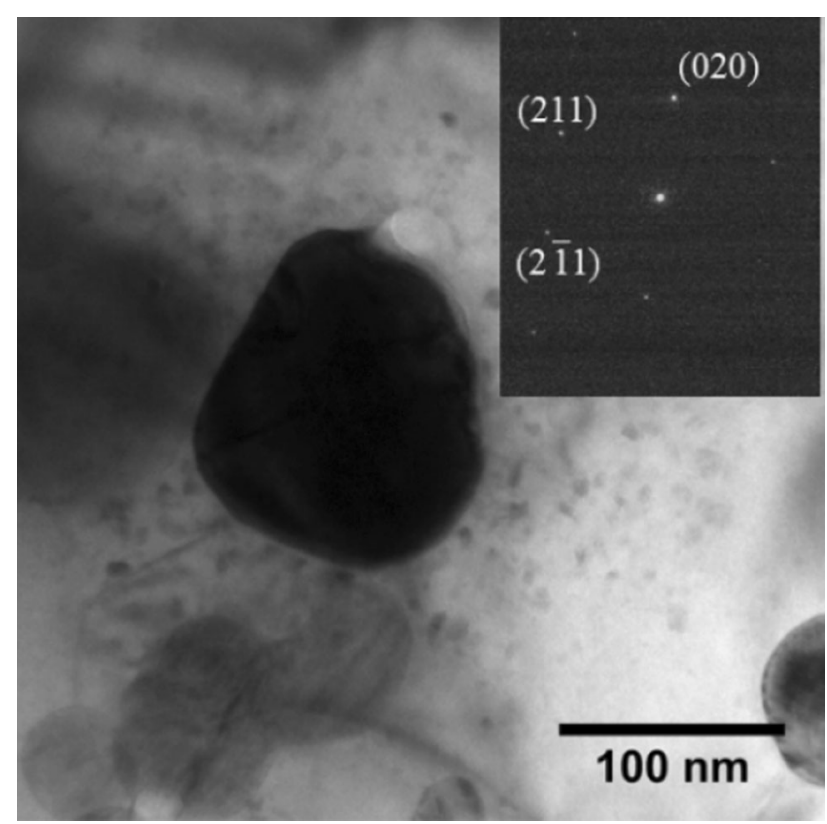

Fig. 7-Diffraction patterns obtained from the precipitate indexed with the reflections of BCC crystal structure. The zone axis of the pattern is along $[10 \overline{2}]$.

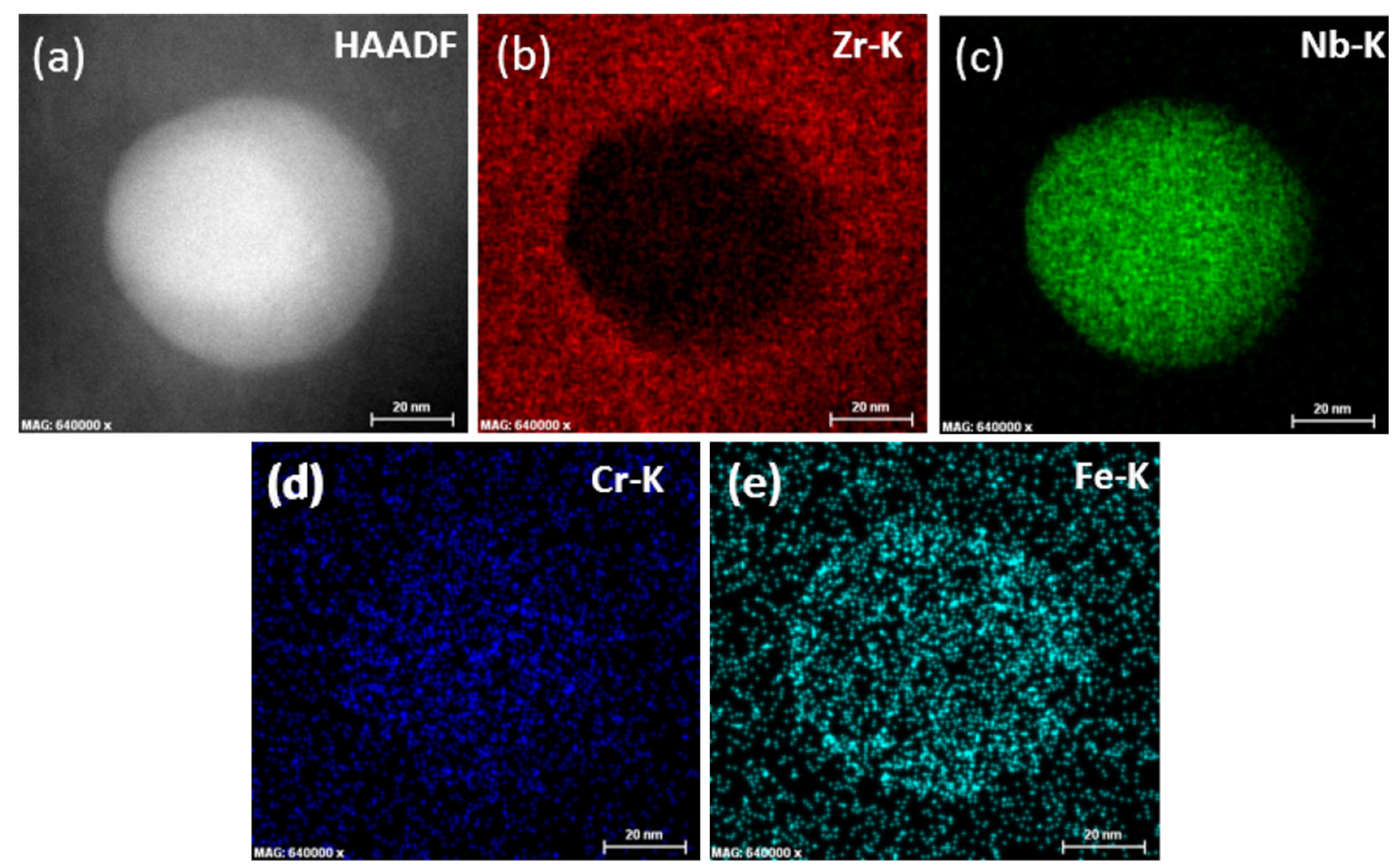

Fig. 6- (a) HAADF-STEM image of a precipitate surrounded by the matrix. (b) through (e) EDS elemental mapping of the precipitate and the matrix. 


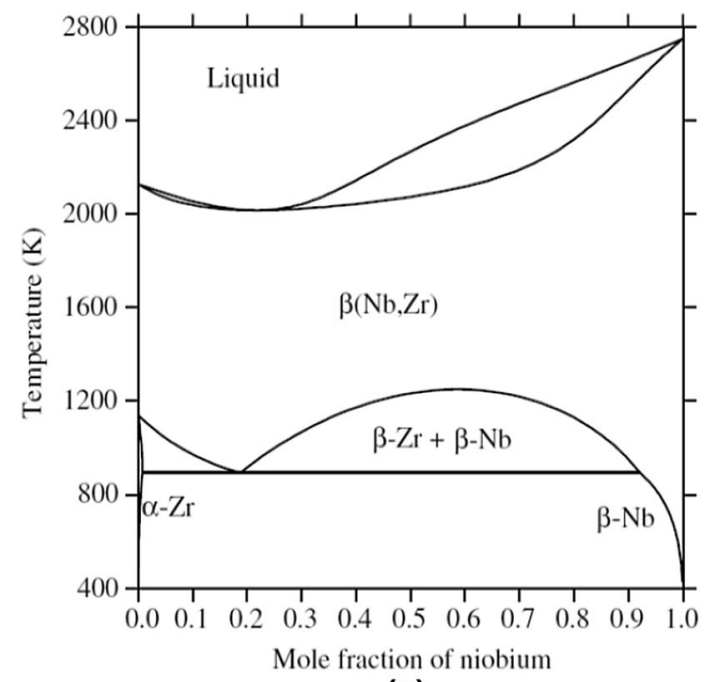

(a)

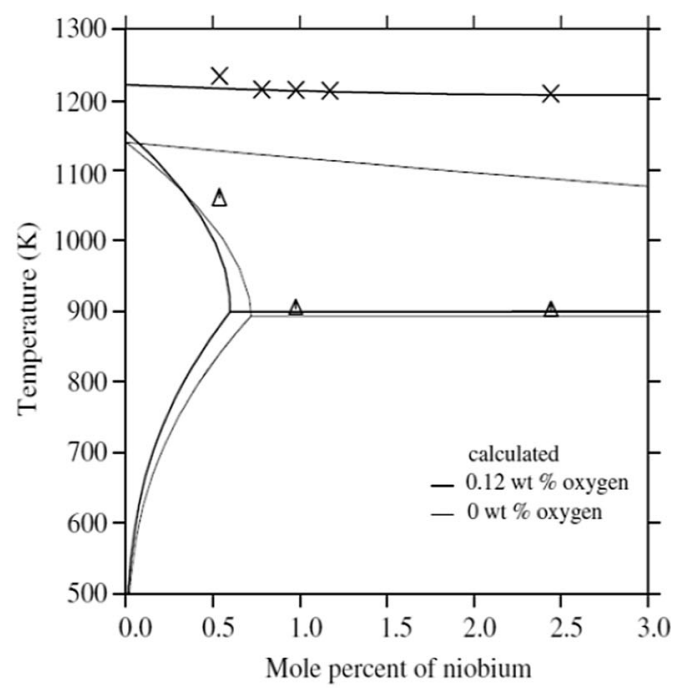

(b)

Fig. 8- (a) Zr-Nb phase diagram, (b) an expanded view of the $\mathrm{Zr}$-rich side in the $\mathrm{Zr}$ - $\mathrm{Nb}$ phase diagram. ${ }^{[29]}$

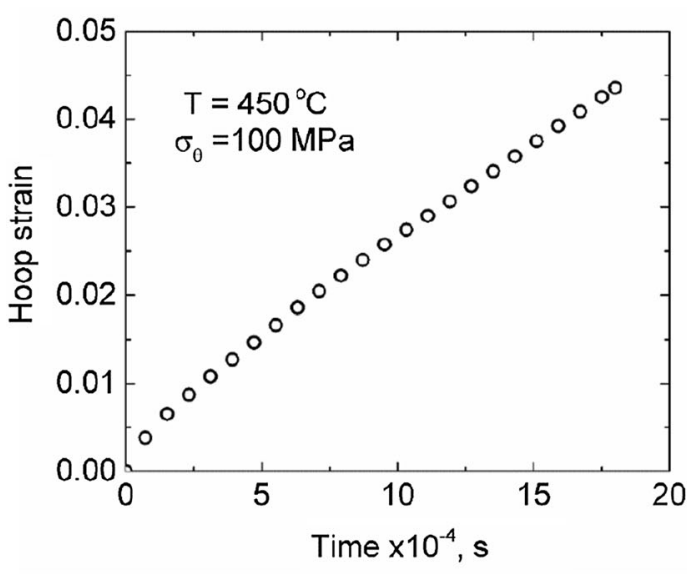

(a)

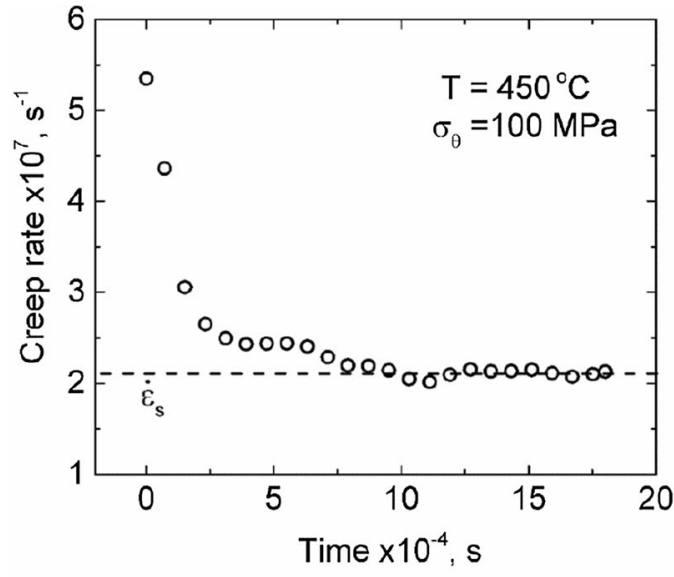

(b)

Fig. 9-(a) The creep curve of HANA-4 at $100 \mathrm{MPa}$ and $723 \mathrm{~K}\left(450^{\circ} \mathrm{C}\right)$. (b) Creep rate $v s$ time plot showing the steady-state creep rate.

Table II. Stress, Steady-State Creep Rates, and Total Strain at the Three Different Test Temperatures

\begin{tabular}{|c|c|c|c|c|c|c|c|c|c|c|c|}
\hline \multicolumn{4}{|c|}{$673 \mathrm{~K}\left(400^{\circ} \mathrm{C}\right)$} & \multicolumn{4}{|c|}{$723 \mathrm{~K}\left(450^{\circ} \mathrm{C}\right)$} & \multicolumn{4}{|c|}{$773 \mathrm{~K}\left(500^{\circ} \mathrm{C}\right)$} \\
\hline $\begin{array}{l}\sigma_{\theta} \\
(\mathrm{MPa})\end{array}$ & $\sigma_{\theta} / E$ & $\dot{\varepsilon}_{\mathrm{s}}\left(\mathrm{s}^{-1}\right)$ & $\begin{array}{c}\varepsilon \\
\text { (pct) }\end{array}$ & $\begin{array}{c}\sigma_{\theta} \\
(\mathrm{MPa})\end{array}$ & $\sigma_{\theta} / E$ & $\dot{\varepsilon}_{\mathrm{s}}\left(\mathrm{s}^{-1}\right)$ & $\begin{array}{c}\varepsilon \\
\text { (pct) }\end{array}$ & $\begin{array}{c}\sigma_{\theta} \\
(\mathrm{MPa})\end{array}$ & $\sigma_{\theta} / E$ & $\dot{\varepsilon}_{\mathrm{s}}\left(\mathrm{s}^{-1}\right)$ & $\varepsilon(\mathrm{pct})$ \\
\hline 90 & $1.27 \times 10^{-3}$ & $7.3 \times 10^{-9}$ & 0.8 & 20 & $2.96 \times 10^{-4}$ & $1.3 \times 10^{-9}$ & 0.2 & 5.4 & $8.38 \times 10^{-5}$ & $4.2 \times 10^{-9}$ & 0.4 \\
\hline 106 & $1.50 \times 10^{-3}$ & $1.3 \times 10^{-8}$ & 1.2 & 25 & $3.70 \times 10^{-4}$ & $1.0 \times 10^{-9}$ & 0.5 & 8.2 & $1.27 \times 10^{-4}$ & $3.4 \times 10^{-9}$ & 0.6 \\
\hline 119 & $1.68 \times 10^{-3}$ & $2.3 \times 10^{-8}$ & 0.6 & 30 & $4.44 \times 10^{-4}$ & $3.0 \times 10^{-9}$ & 0.2 & 10.6 & $1.64 \times 10^{-4}$ & $7.5 \times 10^{-9}$ & 1.1 \\
\hline 122 & $1.72 \times 10^{-3}$ & $2.1 \times 10^{-8}$ & 1.5 & 40 & $5.92 \times 10^{-4}$ & $5.0 \times 10^{-9}$ & 0.2 & 13 & $2.02 \times 10^{-4}$ & $7.3 \times 10^{-9}$ & 0.9 \\
\hline 134 & $1.89 \times 10^{-3}$ & $3.9 \times 10^{-8}$ & 0.6 & 50 & $7.39 \times 10^{-4}$ & $1.2 \times 10^{-8}$ & 0.5 & 19 & $2.95 \times 10^{-4}$ & $7.1 \times 10^{-9}$ & 0.4 \\
\hline 137.5 & $1.94 \times 10^{-3}$ & $3.2 \times 10^{-8}$ & 1.1 & 50 & $7.39 \times 10^{-4}$ & $1.3 \times 10^{-8}$ & 0.6 & 30 & $4.65 \times 10^{-4}$ & $2.9 \times 10^{-8}$ & 1.2 \\
\hline 156 & $2.20 \times 10^{-3}$ & $6.2 \times 10^{-8}$ & 1.7 & 61 & $9.02 \times 10^{-4}$ & $2.1 \times 10^{-8}$ & 0.5 & 44 & $6.82 \times 10^{-4}$ & $8.3 \times 10^{-8}$ & 1.2 \\
\hline 177 & $2.50 \times 10^{-3}$ & $9.3 \times 10^{-8}$ & 1.5 & 65 & $9.61 \times 10^{-4}$ & $3.0 \times 10^{-8}$ & 0.2 & 53 & $8.22 \times 10^{-4}$ & $1.4 \times 10^{-7}$ & 2.8 \\
\hline \multirow[t]{3}{*}{203} & $2.87 \times 10^{-3}$ & $2.6 \times 10^{-8}$ & 2.1 & 70 & $1.04 \times 10^{-3}$ & $8.8 \times 10^{-8}$ & 1.7 & 69 & $1.07 \times 10^{-3}$ & $4.8 \times 10^{-7}$ & 4.9 \\
\hline & & & & 99 & $1.46 \times 10^{-3}$ & $3.1 \times 10^{-7}$ & 4.5 & 90 & $1.40 \times 10^{-3}$ & $1.4 \times 10^{-6}$ & 7.4 \\
\hline & & & & 100 & $1.48 \times 10^{-3}$ & $2.1 \times 10^{-7}$ & 4.4 & 90 & $1.40 \times 10^{-3}$ & $1.3 \times 10^{-6}$ & 10.8 \\
\hline
\end{tabular}

$\sigma_{\theta}$, hoop stress; $E$, elastic modulus; $\dot{\varepsilon}_{s}$, steady-state creep rate; $\varepsilon$, total strain. 


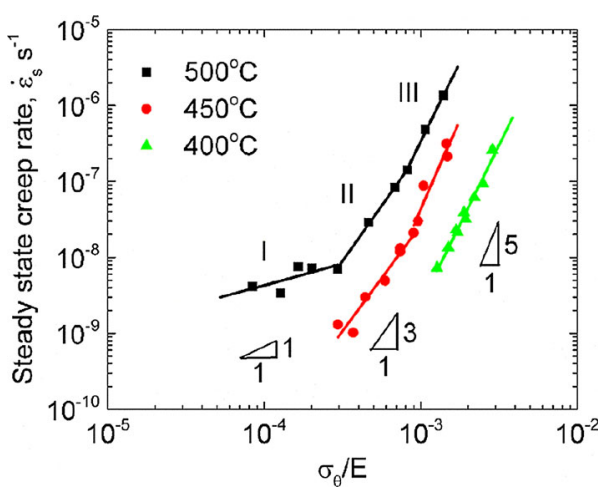

Fig. 10 - Steady-state creep rate vs modulus-compensated hoop stress.

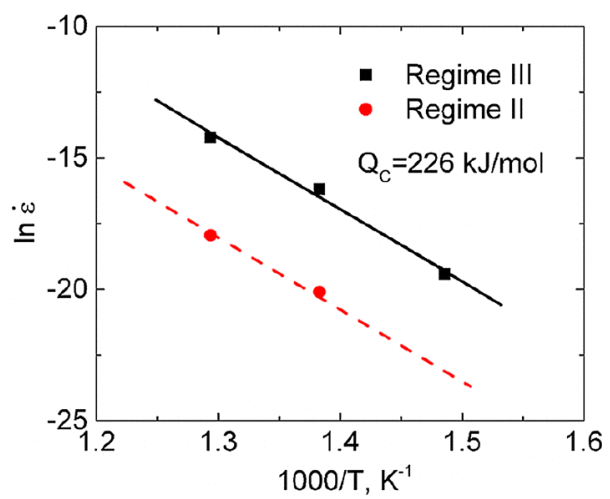

Fig. 11-Arrhenius plots used for calculating the activation energy at a constant normalized hoop stress for regimes II and III.

compensated stress at a constant temperature which is shown in Figure 10. As seen from the plot pertained to the tests at $773 \mathrm{~K}\left(500{ }^{\circ} \mathrm{C}\right), n$ is $0.6 \pm 0.3$ at low stresses, which changes to $4.2 \pm 0.1$ at high stresses passing through $n=2.9 \pm 0.1$ at the intermediate stress regime indicating transitions in creep mechanisms as the applied stress increases. These regimes will be referred to as regime I, II, and III at low, intermediate, and high stresses, respectively. A similar trend can be observed at $723 \mathrm{~K}$ and $673 \mathrm{~K}\left(450{ }^{\circ} \mathrm{C}\right.$ and $\left.400{ }^{\circ} \mathrm{C}\right)$ as well except for the absence of the creep data at lower stresses.

At a constant modulus-compensated stress, the general creep Eq. [3a] can simply be written as,

$$
\dot{\varepsilon}_{\mathrm{S}}=A_{0} \mathrm{e}^{-\frac{Q_{\mathrm{c}}}{R T}},
$$

where $A_{0}$ is a function of the applied stress. The activation energy was then calculated from the slope of a semi-logarithmic plot of the steady-state creep rate $v s$ the inverse of temperature as shown in Figure 11. A creep activation energy value of $226 \mathrm{~kJ} / \mathrm{mol}$ was determined for both regimes II and III. However, the activation energy for regime I could not be assessed owing to the lack of creep data at lower temperatures. The activation energy estimated for regimes II and III is somewhat lesser than the activation energy for lattice self-diffusion for $\alpha$-Zr determined by radioactive tracer experiments, which is $259 \mathrm{~kJ} / \mathrm{mol} \cdot{ }^{[32]}$ However, the value

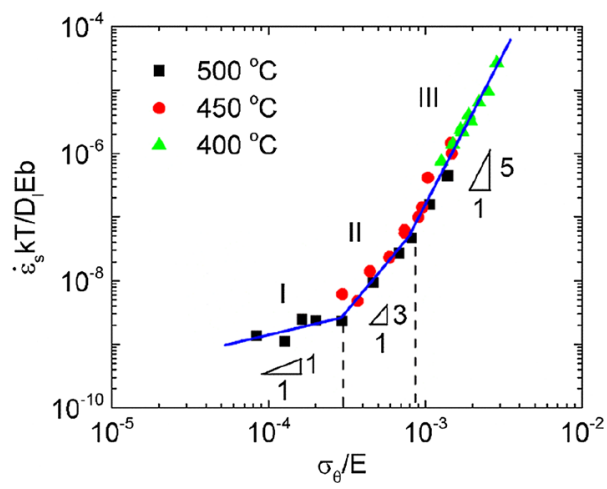

Fig. 12-Normalized steady-state creep rate vs normalized hoop stress.

is comparable to the lattice diffusion activation energies of $213 \mathrm{~kJ} / \mathrm{mol}$ and $234 \mathrm{~kJ} / \mathrm{mol}$ obtained from creep experiments in $\mathrm{Zr}-1$ petNb alloys by Voeikov et al. ${ }^{\left[{ }^{[}\right]}$ and Alymov et al. ${ }^{[17]}$, respectively. Further, the creep data are presented as the plot of the steady-state creep rates normalized by the lattice diffusivity $\left(D_{1}=D_{0} \exp \left(-\frac{Q_{\mathrm{c}}}{R T}\right)\right)$ vs the modulus-compensated stress in Figure 12. The diffusion coefficient, $D_{0}$, and $Q_{\mathrm{c}}$ assumed the values of $5 \times 10^{-4} \mathrm{~m}^{2} / \mathrm{s}$ and $259 \mathrm{~kJ} / \mathrm{mol}$, respectively, as determined for $\mathrm{Zr}-1.3 \mathrm{pctSn}$ from radioactive tracer data. ${ }^{[32]}$ It can be seen in this figure that the steady-state creep rates obtained at different test temperatures overlapped well showing the transitions in the value of stress exponents and possibly in creep mechanisms as the applied hoop stress increases; Regime I with a stress exponent close to 1 transits into regime II with $n \sim 3$ at a stress of about $2.95 \times 10^{-4} E$, which further changes to regime III with $n \sim 4.5$ at about $8.22 \times 10^{-4} E$.

\section{Crept Microstructures}

The deformation microstructure of the specimens crept in regime II revealed dislocations distributed throughout the matrix with little sub-boundaries formation as seen in Figure 13(a). Predominant number of dislocations were observed to be pinned at the precipitates with the unpinned portion of the dislocation lines advanced further with bows (curves) in the matrix as seen in Figure 13(b). Further, the dislocations were imaged using weak-beam dark field technique in order to observe the interaction of the dislocation lines with the precipitates (Figure 14). It can be seen from the micrographs that dislocations were captured while bypassing the precipitates possibly assisted by dislocation climb process, which are marked as 'A.' As well, dislocation lines were observed to be partially wrapping around the precipitates in a way they are in the process of bypassing the precipitates through Orowan bowing, which are marked as 'B.' The curvature formed by the dislocations in between precipitates generally indicates the direction in which the shear stress acts on the dislocation line.

On the other hand, the micrographs of the crept specimen in regime III showed dislocations forming 


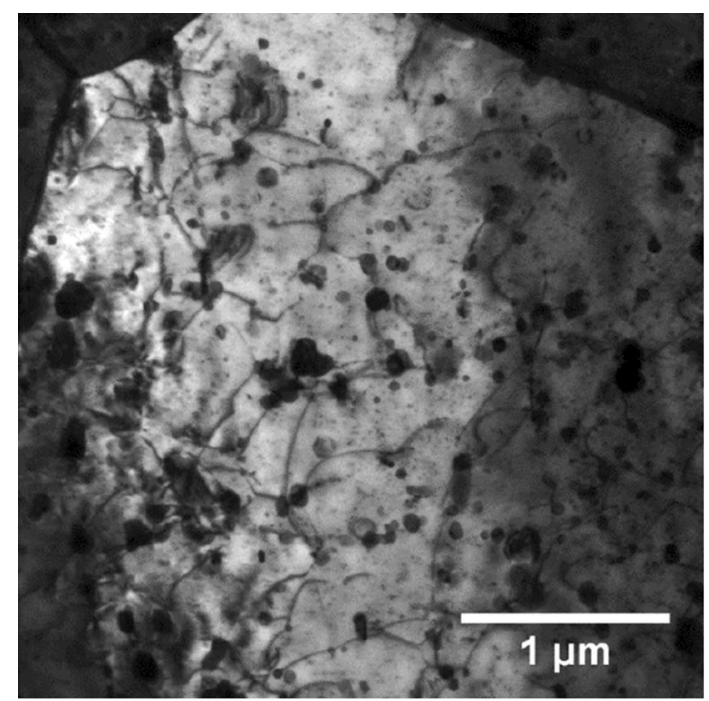

(a)

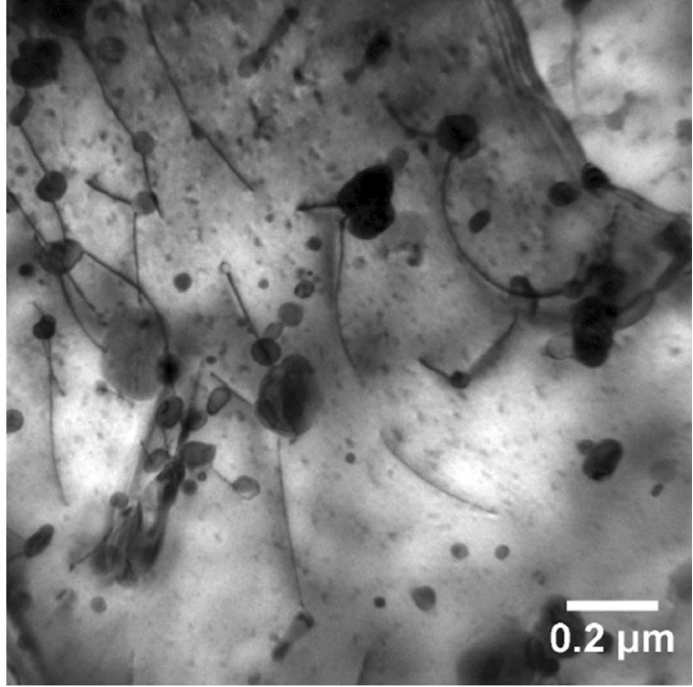

(b)

Fig. 13-TEM micrographs of the crept specimen at $50 \mathrm{MPa}$ and $723 \mathrm{~K}\left(450{ }^{\circ} \mathrm{C}\right)$ in regime II $(n=3)$. $(a)$ Dislocations are distributed throughout the matrix without forming sub-boundaries and networks. (b) A higher magnification image showing dislocations pinned by the precipitates.
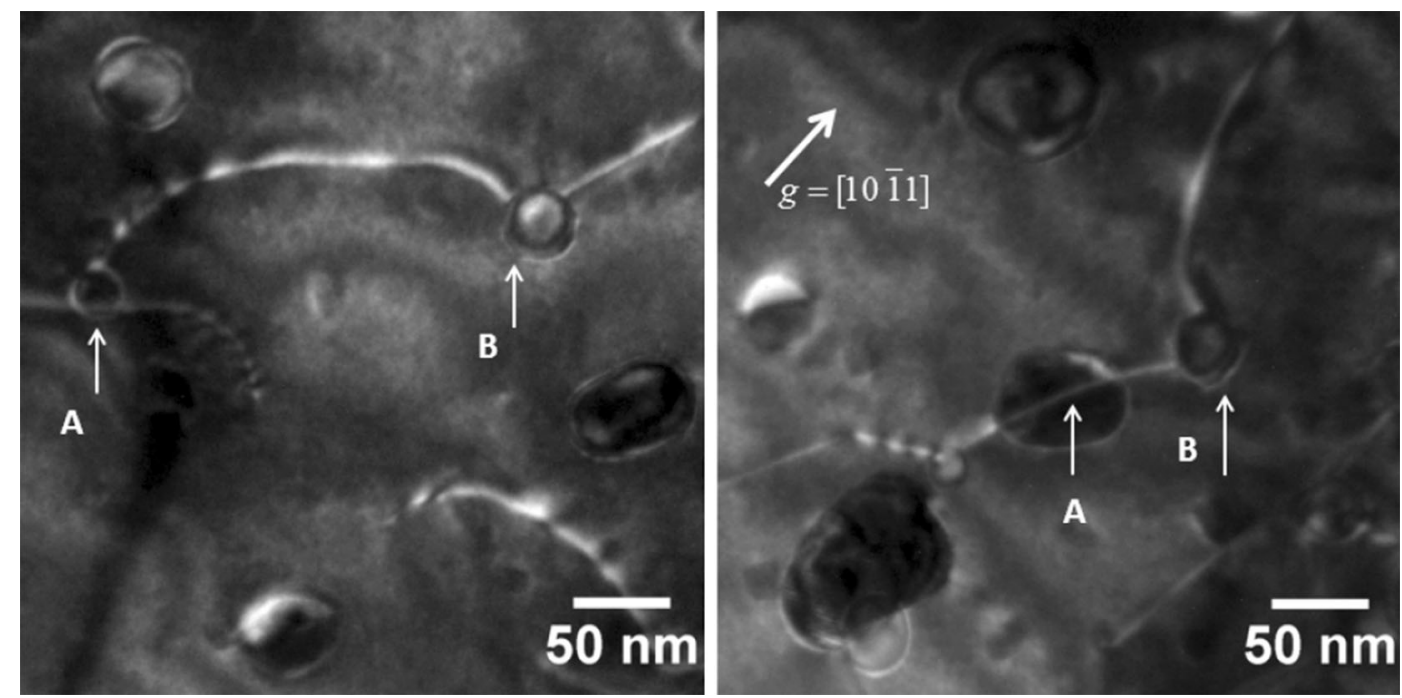

Fig. 14 - Weak-beam dark field TEM images showing dislocations climbing over precipitates (marked as 'A') and partially bowing around precipitates in a similar way of that in the Orowan bypass mechanism (marked as ' $\mathrm{B}$ ').

hexagonal networks as well as sub-grain boundaries which were distinctly absent in regime II as shown in Figure 15. Further, the dislocation density inside the sub-grains was evidently low. These observations suggest that the dislocations could overcome the precipitates in regime III at a relative ease making the interruption by them probably an insignificant process toward the rate-controlling mechanism.

\section{DISCUSSION}

\section{A. Rate-controlling Mechanism in Regime I}

A stress exponent close to 1 at low stresses indicates that any of the diffusional creep mechanisms such as Coble creep, Nabarro-Herring $(\mathrm{N}-\mathrm{H})$ creep, or Harper-Dorn
(H-D) creep can be the dominant mechanism. ${ }^{[33-36]}$ But pointing out the exact rate-controlling mechanism necessitates the activation energy data or the knowledge of the dependency of the creep rate on the change in grain size (inverse grain size exponent), which are unavailable for regime $I^{[37]}$ However, it can be suggested based on the earlier studies on zirconium alloys that Coble creep is more likely the rate-controlling mechanism owing to the distribution of fine grain size in HANA-4, which has an average of $3.6 \mu \mathrm{m}$. Generally, $\mathrm{N}-\mathrm{H}$ creep and $\mathrm{H}-\mathrm{D}$ creep are the dominant mechanisms in materials with intermediate and large grain sizes, respectively. For instance, the creep data of $\alpha-\mathrm{Zr}$ from Novotný et al. exhibited an inverse grain size exponent of $\sim 3$ up to a grain size of $125 \mu \mathrm{m}$ suggesting Coble creep to be active at $673 \mathrm{~K}$ $\left(600^{\circ} \mathrm{C}\right) \cdot{ }^{[38]}$ In specimens with larger grain size than 

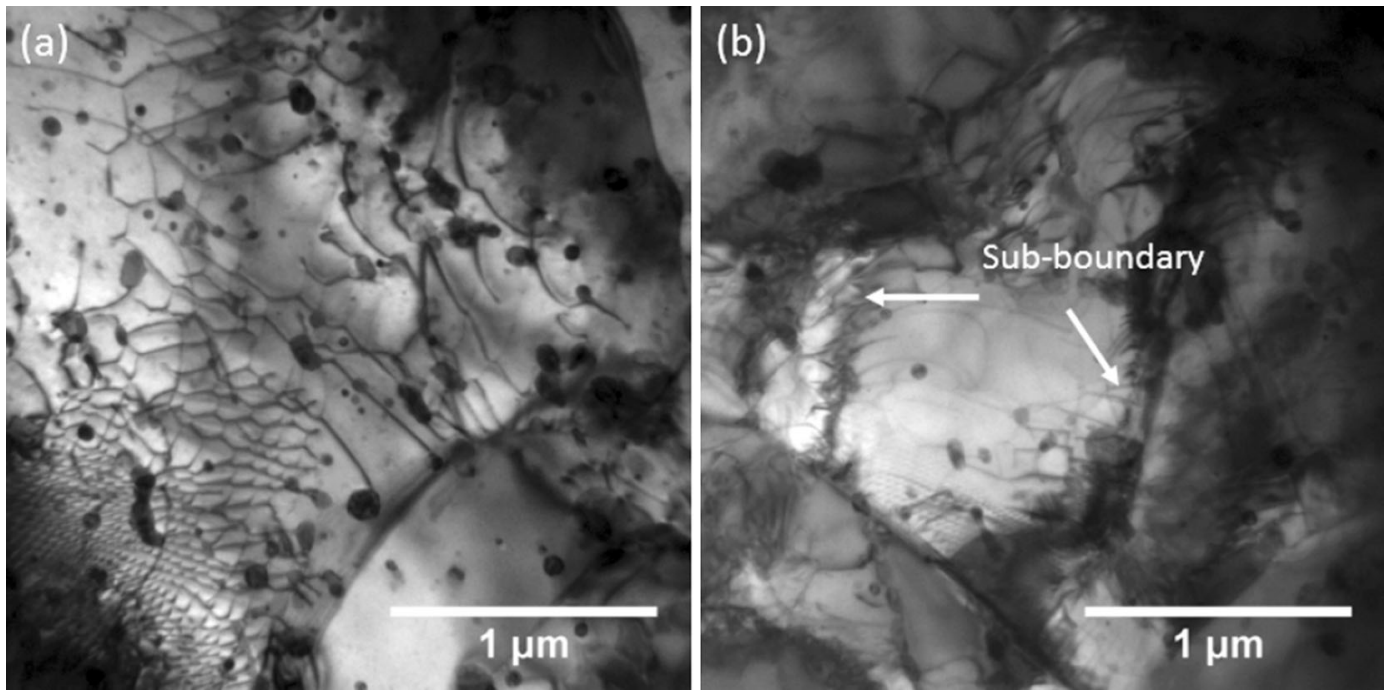

Fig. 15-TEM micrographs of the crept specimen at $99 \mathrm{MPa}$ and $723 \mathrm{~K}\left(450{ }^{\circ} \mathrm{C}\right)$ in regime III $(n=4.5)$. $(a)$ Dislocations forming into networks inside grains, (b) dislocations forming into sub-boundaries with lesser dislocation density inside the sub-grain.

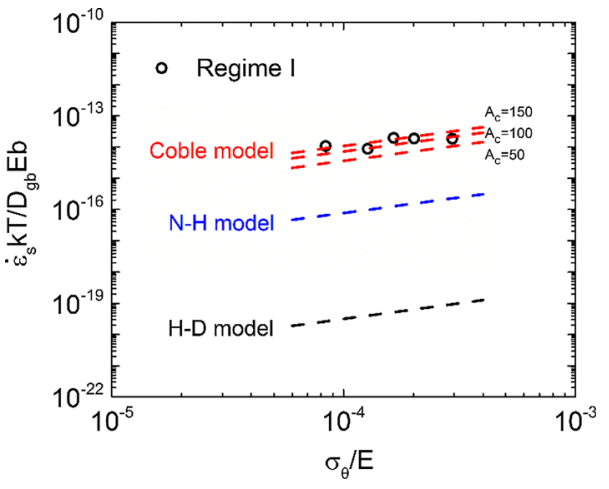

Fig. 16-Comparison of the experimental creep rates in regime I with the Coble creep model.

$125 \mu \mathrm{m}$, the inverse grain size exponent value reduced to zero indicating that $\mathrm{H}-\mathrm{D}$ creep is the rate-governing mechanism. Also in another work of the authors, ${ }^{[39]}$ Coble creep was found to be operable in Zircaloy-4 with an average grain size of $8.5 \mu \mathrm{m}$ at low stresses in the temperature range from $773 \mathrm{~K}$ to $873 \mathrm{~K}\left(500{ }^{\circ} \mathrm{C}\right.$ to $600{ }^{\circ} \mathrm{C}$ ) based on the observation that the creep activation energy value $(196 \mathrm{~kJ} / \mathrm{mol})$ lied closed to the grain-boundary diffusion energy ( $188 \mathrm{~kJ} / \mathrm{mol}$ ) in $\alpha$ - $\mathrm{Zr}$ determined using radioactive tracer data. ${ }^{[40]}$ Further, the experimental creep results in regime I are compared with the predictions by the Coble creep model given by the relation,

$$
\begin{aligned}
\frac{\dot{\varepsilon}_{\mathrm{s}} k T}{D_{\mathrm{gb}} E b} & =(100 \pm 50)\left(\frac{b}{d}\right)^{3}\left(\frac{\sigma}{E}\right)^{1} \\
D_{\mathrm{gb}} & =D_{0 \mathrm{gb}} \exp \left(-\frac{Q_{\mathrm{gb}}}{R T}\right),
\end{aligned}
$$

where $A_{\mathrm{c}}$ is a constant which was derived to be equal to $(100 \pm 50),{ }^{[33,41]} d$ is the average grain size $(3.6 \mu \mathrm{m})$, and $D_{\mathrm{gb}}$ is the grain boundary diffusivity. $D_{0 \mathrm{gb}}$ and
$Q_{\mathrm{gb}}$ are the grain-boundary diffusivity coefficient and the grain-boundary diffusion activation energy, which have the values of $10^{-3} \mathrm{~m}^{2} / \mathrm{s}$ and $188 \mathrm{~kJ} / \mathrm{mol}$ determined for $\alpha-\mathrm{Zr}$ using radioactive tracer data. ${ }^{[40]}$ Additionally, the predictions by the models for $\mathrm{N}-\mathrm{H}$ creep $^{[36]}$ and $\mathrm{H}-\mathrm{D}$ creep $^{[42]}$ were calculated using Eqs. [6] and [7], respectively,

$$
\begin{aligned}
& \frac{\dot{\varepsilon}_{\mathrm{s}} k T}{D_{1} E b}=12\left(\frac{b}{d}\right)^{2}\left(\frac{\sigma}{E}\right)^{1} \\
& \frac{\dot{\varepsilon}_{\mathrm{s}} k T}{D_{1} E b}=4 \times 10^{-11}\left(\frac{\sigma}{E}\right)^{1}
\end{aligned}
$$

Figure 16 compares the experimental creep rates in regime I with the model predictions for Coble, $\mathrm{N}-\mathrm{H}$, and $\mathrm{H}-\mathrm{D}$ creep mechanisms as a BMD plot. As seen, the predictions by the Coble creep model exhibit an excellent correlation with the experimental results, thus substantiating the dominance of the Coble creep mechanism in HANA-4 at low stresses. On the other hand, the creep rates predicted by the $\mathrm{N}-\mathrm{H}$ and the $\mathrm{H}-\mathrm{D}$ models fell about 2 and 5 orders of magnitude, respectively, below the creep rates measured in regime I. Therefore, these mechanisms are not considered to be rate controlling in the HANA-4 tubing.

\section{B. Rate-Controlling Mechanism in Regime II}

A stress exponent of 3 with the creep activation energy equivalent to that of the lattice self-diffusion activation energy in regime II generally points to dislocation glide or microcreep as the rate-controlling mechanism $^{[43]}$ as pointed out earlier. In fact, the creep deformation of several Nb-added Zircaloys in $n=3$ regime has been ascribed to dislocation glide-controlled mechanism arising from locking of gliding dislocations by niobium solute atoms,${ }^{[3]}$ which was as well validated by TEM micrographs revealing uniform distribution of 

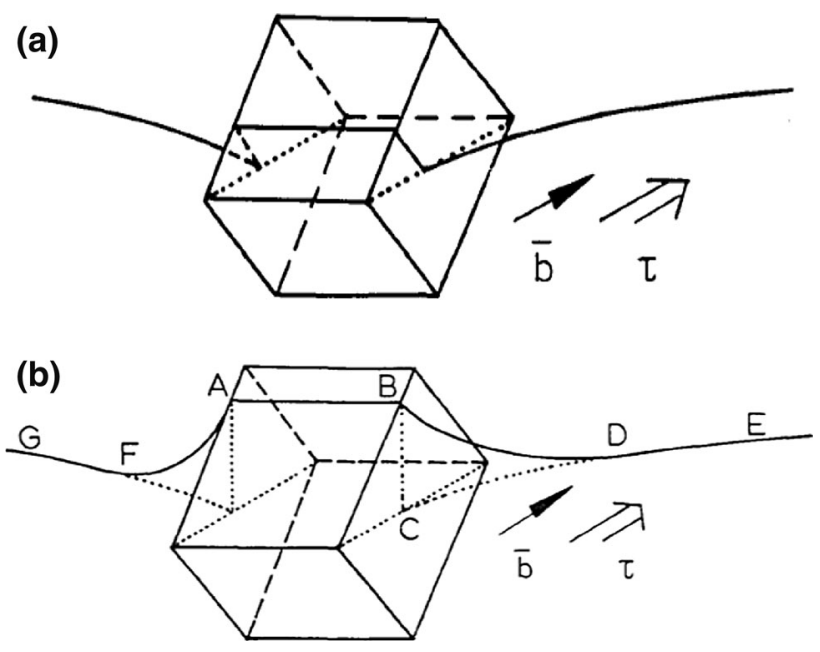

Fig. 17-Schematic diagrams depicting (a) local climb and $(b)$ general climb of dislocation over cubical precipitate. ${ }^{[51]}$

dislocations in grain interior. Although the deformation microstructures of HANA-4 in regime II showed dislocations presented throughout the matrix, it is quite evident from the micrographs that those dislocations were pinned at the precipitates (Figure 13(a)). This indicates that dislocations could more likely move at ease while gliding in between two consecutive precipitates without being locked by niobium solute atoms, if anything present. Moreover, very limited solubility of niobium in zirconium [0.3 wt pet of $\mathrm{Nb}$ at $773 \mathrm{~K}$ $\left(500{ }^{\circ} \mathrm{C}\right)$ ] possibly leaves little solute atoms available in the matrix for locking dislocations to reduce their glide rate. Based on these observations, dislocation glide resulting from solute locking as the rate-controlling mechanism, which has been generally attested to the $n=3$ regime in $\mathrm{Zr}-\mathrm{Nb}$ alloys, becomes questionable in regime II of HANA-4 alloy. It is worth pointing out here that while $\mathrm{Sn}$ is present as solid solution in $\mathrm{Zr}$, Zircaloy-4 was shown not to exhibit viscous glide creep. ${ }^{[11,39]}$ On the other hand, dislocations bypassing the precipitates, which is the slower process, can be the rate-governing mechanism in regime II.

An activation energy equivalent to that for the lattice self-diffusion in conjunction with the observation of dislocations passing over the precipitates in the crept microstructure (Figure 14) indicates that dislocation climb over the Nb-rich precipitates as the rate-controlling mechanism in regime II. Dislocation climb over obstacles as the rate-controlling mechanism has been extensively investigated especially in precipitation-hardened and dispersion-strengthened materials. ${ }^{[25,44-51]}$ Local climb and general climb are the two mechanisms that have been often postulated as the modes of dislocations bypassing second-phase particles at relatively low stresses and high temperatures, wherein diffusion occurs at a reasonably faster rate. ${ }^{[46,52]}$ In local climb, the dislocation line assumes the profile of the particle at the particle-matrix interface, while the rest of the dislocation line glides on the slip plane thus creating a sharp curvature (Figure 17(a)). On the other hand, in the case of general climb, the dislocation line outside the particle gets relaxed by forming a smooth curvature at the interface through diffusion of vacancies to the core (Figure 17(b)). Although both these mechanisms were suggested to be operative in precipitation hardened as well as dispersion-strengthened materials through experiments and mathematical models, it necessitates a discrete analysis to figure out from which one of these mechanisms is operative in HANA-4, which has not been attempted. ${ }^{[52]}$ However, Rösler and Arzt demonstrated using their model that general climb is favorable energetically and predominates when dislocations bypass precipitates in materials with low volume fraction of precipitates and without any long range attractive dislocation-precipitate interactions. ${ }^{[46]}$ The force of the attractive or repulsive interaction between matrix and precipitates increases proportional to the difference in their physical parameters, namely, lattice parameter and shear modulus, which are listed for HANA-4 in Table III. As seen from Table III, the lattice parameter and the shear modulus of the zirconium matrix and the $\beta$ - Nb precipitates lie closely indicating that the dislocation-particle long range interaction would be very small. For instance, the repulsive force due to the modulus mismatch exerted by a $\beta-\mathrm{Nb}$ precipitate on an edge dislocation located at the particle-matrix interface in HANA-4 is calculated to be $6.4 \times 10^{-11} \mathrm{~N}$ at $723 \mathrm{~K}\left(450{ }^{\circ} \mathrm{C}\right)$ using the equations derived by Weeks et al. (Figure 18). ${ }^{[53]}$ For comparison, this value is about 6.7 times smaller than the force calculated between $\mathrm{Al}_{3} \mathrm{Sc}$ particles and matrix at $673 \mathrm{~K}$ $\left(400{ }^{\circ} \mathrm{C}\right)$ in $\mathrm{Al}-4 \mathrm{Mg}-0.3 \mathrm{Sc}$ system, in which detachment of dislocations from particles was demonstrated to be the rate-controlling mechanism. ${ }^{[49]}$ Moreover, HANA-4 has a low volume fraction of $\beta-\mathrm{Nb}$ precipitates in accordance with the assumption of the Rösler and Arzt model. It can be therefore conjectured that general climb occurs predominantly in regime II of HANA-4. As well, Röser and Arzt derived a stress exponent of 3 to 4 for the general climb-controlled creep regime, which matches with the stress exponent of 3 obtained in regime II further substantiating dislocation climb, as opposed to dislocation glide, as the rate-controlling mechanism in HANA-4. ${ }^{[46]}$

\section{Rate-Controlling Mechanism in Regime III}

A stress exponent of $\sim 4.5$ and an activation energy close to the lattice self-diffusion activation energy in regime III indicates any of glide of jogged screw dislocations or edge dislocation climb as the ratecontrolling mechanism. ${ }^{[54-56]}$ However, the presence of sub-boundaries and dislocation network attests the later mechanism as the dominant one, whose mathematical formulation was derived by Weertman. ${ }^{[23,57]}$ According to this model, dislocations glide with less resistance on their slip plane till they arrive closer to other dislocations with the opposite burgers vectors in the parallel slip planes and form dislocation dipoles. Further, these dislocations climb up or down to combine and get annihilated thus allowing further glide to proceed. Between these sequential processes of glide and climb, the later proceeds at a slower rate thus controlling the 
Table III. Lattice Parameters and Shear Modulus of the Zr Matrix and $\beta$-Nb Precipitates

\begin{tabular}{lll}
\hline Parameters & Zr Matrix & $\beta$-Nb Precipitates \\
\hline Lattice Parameter $(\AA)$ & $a=3.23^{[65]}$ & $a_{\mathrm{p}}=3.28^{[62]}$ \\
Shear Modulus at $723 \mathrm{~K}\left(450^{\circ} \mathrm{C}\right)(\mathrm{GPa})$ & $\mu=25^{[31]}$ & $\mu_{\mathrm{p}}=30^{[66]}$ \\
\hline
\end{tabular}

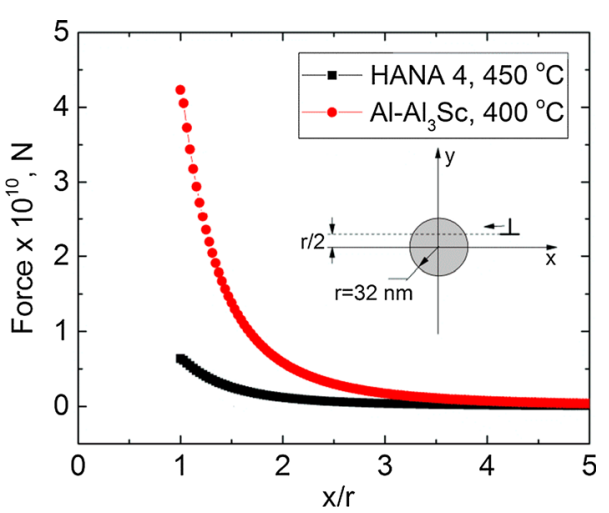

Fig. 18-The repulsive force between an edge dislocation and a precipitate is plotted as function the separation distance in HANA-4 and $\mathrm{Al}-\mathrm{Al}_{3} \mathrm{Sc}$ systems.

deformation process. The rate equation derived by Weertman based on these assumptions has the following form ${ }^{[58]}$

$$
\dot{\varepsilon}_{\mathrm{s}}=\alpha\left(\frac{D_{l}}{b^{3.5} M^{0.5}}\right)\left(\frac{\sigma}{G}\right)^{4.5}\left(\frac{G \Omega}{k T}\right)
$$

where $\alpha$ is a constant whose values are in the range $0.015<\alpha<0.33, M$ is the number of active dislocation sources in a unit volume, $G$ is the shear modulus, $\Omega$ is the atomic volume, $D_{1}=5 \times 10^{-4}$ $\exp \left(-\frac{25900}{R T}\right) \mathrm{m}^{2} / \mathrm{s}^{[32]}$, and the rest are as described before. As noted, the stress exponent was derived to be 4.5. The value of $M$ can be related to the dislocation density in the annealed material under consideration as, ${ }^{[59]}$

$$
M=0.27 \rho^{1.5}
$$

The value of $\mathrm{M}$ was earlier estimated for annealed Zircaloy-4 to be about, $7.6 \times 10^{16} / \mathrm{m}^{3}$, which could be applicable to annealed HANA-4 as well. ${ }^{[39]}$ Substituting $\alpha \sim 0.1$ and $\Omega \sim 0.7 b^{3}$ and $E=2.6 G$ with other values, Eq. [8] can be written in the BMD format as,

$$
\frac{\dot{\varepsilon}_{\mathrm{s}} k T}{D_{1} E b}=1.22 \times 10^{6}\left(\frac{\sigma}{E}\right)^{4.5}
$$

The experimental creep results in regime III were then compared with the Weertman model as given in Eq. [10] (Figure 19), which shows a good correlation between them indicating climb of edge dislocations as the ratecontrolling mechanism in regime III of HANA-4. Further, an important signature in the crept microstructure of the dislocation climb-controlled process is the formation of sub-grain boundaries and dislocation networks, which were indeed observed in the HANA-4 specimens deformed in regime III (Figure 15).

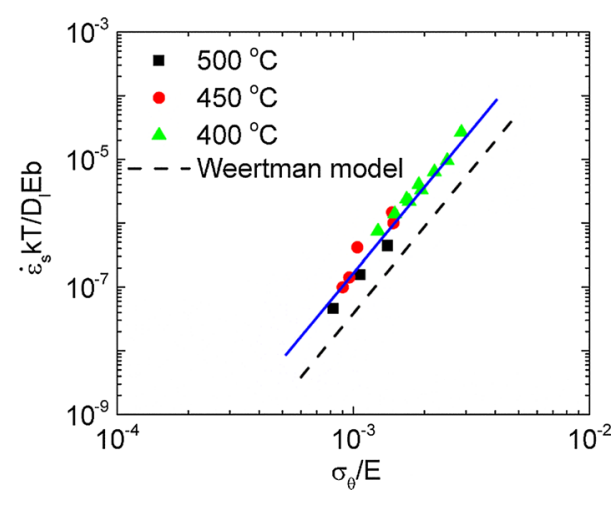

Fig. 19-Comparison of the experimental creep rates in regime III with the Weertman climb model.

Based on the analyses of the creep data and the microstructural evidences, it can be suggested that dislocation climb is the rate-controlling mechanism in both regimes II and III, respectively, at low and high stresses. Notably, the activation energies for creep in regimes II and III are similar which are close to the lattice self-diffusion activation energy, thus supporting this proposition. However, the difference between the climb processes in regimes II and III would be that only the segments of dislocations approaching the precipitates would climb over them to bypass (a local phenomenon) and then start gliding on the same slip plane as the former one, whereas the entire dislocation line would climb to get annihilated or to form sub-boundaries on the parallel slip planes in the latter case (a global phenomenon).

\section{Transition from Regime II to Regime III}

A question arises as to what causes the transition from regime II at low stresses to regime III at high stresses. It can be argued that dislocations start overcoming the precipitates through a mechanism other than the climb process in regime III above the hoop stress of about $8.22 \times 10^{-4} E$. At high enough stresses, precipitate shearing and Orowan bowing between precipitates, which are essentially athermal processes, are generally considered to be operative for bypassing precipitates by dislocations. In the case of precipitate shearing, the shear stress required to break away from the precipitates can be calculated from the particle strength which may originate from various hardening mechanisms such as misfit strengthening, chemical strengthening, modulus hardening, and order hardening. ${ }^{[25]}$ Since the $\beta-\mathrm{Nb}$ precipitates in HANA-4 have no ordered structure as noticed from the diffraction pattern, only the strengthening owing to the other mechanisms can be considered 
for calculating the shearing stress of the precipitates. The strengthening $\left(\sigma_{\mathrm{m}}\right)$ contributed by the misfit $(\varepsilon)$ between matrix and precipitate can be determined using the relations, ${ }^{[60]}$

$$
\begin{gathered}
\sigma_{\mathrm{m}}=M \chi(\varepsilon \mu)^{3 / 2}\left(\frac{\langle r\rangle f b}{T}\right), \\
\varepsilon=\frac{2}{3}\left(\frac{a_{\mathrm{p}}-a}{a}\right),
\end{gathered}
$$

where $M$ is the Taylor factor that generally assumed a value of 4 for zirconium alloys in the case of uniaxial tensile testing. However, the value of $M$ for biaxial loading is not available in the literature. Therefore, $M$ is assumed to be 4 here. $\chi$ is a constant whose value is 2.5, $\mu$ is the shear modulus at the test temperature, $\langle r\rangle$ and $f$ are the average radius and the volume fraction of precipitates, $T$ is the line tension of dislocations, which is roughly equal to $\frac{1}{2} \mu b^{2}$, and $a$ and $a_{\mathrm{p}}$ are the lattice parameters of the matrix and precipitate, respectively. The value of $\langle r\rangle$ is $32 \mathrm{~nm}$ obtained from the precipitate size distribution. The volume fraction $(f)$ of the $\beta-\mathrm{Nb}$ precipitates corresponding to $1.5 \mathrm{wt}$ pet of $\mathrm{Nb}$ in HANA-4 calculated from $\mathrm{Zr}-\mathrm{Nb}$ phase diagram using the lever rule is about 1 pct at $723 \mathrm{~K}$ $\left(450{ }^{\circ} \mathrm{C}\right)$. Substituting the values of $\mu, a$ and $a_{\mathrm{p}}$ given in Table III, the stress required to shear the $\beta$-Nb precipitates that are hardened by the misfit is calculated to be $363 \mathrm{MPa}$ at $723 \mathrm{~K}\left(450{ }^{\circ} \mathrm{C}\right)$. For comparison, the effective stress at the transition point between regimes II and III calculated from the hoop stress using the Von Mises criteria is $53 \mathrm{MPa}$, which is about seven times smaller than the shearing stress of the precipitates hardened by the misfit. With respect to the chemical strengthening mechanism, a simple model equating the work done by the dislocations to create the new particle-matrix interface owing to particle shear would give the following relation for calculating the stress $\left(\sigma_{\mathrm{c}}\right)$ required for particle shearing, ${ }^{[61]}$

$$
\sigma_{\mathrm{c}}=\frac{M \pi \gamma_{\mathrm{s}}\langle r\rangle}{2 b \lambda}
$$

and

$$
\lambda=\left(\sqrt{\frac{\pi}{f}}-2\right) \sqrt{\frac{2}{3}}\langle r\rangle .
$$

Here $\gamma_{\mathrm{s}}$ is the particle-matrix interfacial energy and $\lambda$ is the average inter-precipitate spacing. The interfacial energy for the $\mathrm{Zr}$ matrix and $\beta-\mathrm{Nb}$ precipitates was obtained from the literature to be $0.19 \mathrm{~J} / \mathrm{m}^{2},[62,63]$ which is assumed for the newly formed interface due to particle sharing in HANA-4 as well. Thus, the stress required to shear the $\beta-\mathrm{Nb}$ precipitates in HANA-4 was calculated to be $308 \mathrm{MPa}$. Similarly, the stress $\left(\sigma_{\mathrm{mo}}\right)$ needed to shear the precipitates strengthened by modulus hardening can be stated as, ${ }^{[64]}$

$$
\sigma_{\mathrm{mo}}=0.0055 M\left(\frac{f}{T}\right)\left(\mu_{\mathrm{p}}-\mu\right)^{\frac{3}{2}} b\left(\frac{\langle r\rangle}{b}\right)^{\frac{3 m}{2}-1}
$$

where $\mu_{\mathrm{p}}$ and $\mu$ are the shear modulus of the precipitate and matrix, respectively, and $m$ is a constant whose value is equal to 0.85 . Substituting the modulus values from Table III, the stress required to shear the $\beta-\mathrm{Nb}$ precipitates strengthened by modulus hardening is determined to be about $301 \mathrm{MPa}$, which, similar to the case of misfit hardening and chemical strengthening, is several times higher than the observed stress at the transition between regimes II and III from the creep experiments. Based on these calculations, the precipitate shearing as a mechanism to bypass the precipitates in regime III of HANA-4 can be discounted. In addition, the crept microstructure of the specimens from regime III still revealed essentially rounded precipitates supporting that the particle shearing is not an active mechanism for dislocations to bypass the precipitates in regime III.

The second kind of mechanism by which dislocations can bypass precipitates is through the well-known Orowan bowing, for which the required stress $\left(\sigma_{\mathrm{O}-\mathrm{A}}\right)$ is given by the Orowan-Ashby model, ${ }^{[24]}$

$$
\sigma_{\mathrm{O}-\mathrm{A}}=M \frac{0.83 \mu b}{2 \pi(1-v)^{0.5}} \frac{1}{\lambda} \ln \left(\frac{\sqrt{\frac{2}{3}\langle r\rangle}}{2 b}\right),
$$

where $v$ is the Poisson ratio (0.34). A similar volume fraction of the precipitates (1 pct) is assumed at $773 \mathrm{~K}$ $\left(500{ }^{\circ} \mathrm{C}\right)$ since the difference between them is insignificant. Substituting the other values of the parameters in Eq. [14], the stresses necessary for the Orowan bypass are determined to be 51 and $48 \mathrm{MPa}$, respectively, at $723 \mathrm{~K}$ and $773 \mathrm{~K}\left(450{ }^{\circ} \mathrm{C}\right.$ and $\left.500{ }^{\circ} \mathrm{C}\right)$. On the other side, the effective stresses at the transition point between regimes II and III are obtained to be $53 \mathrm{MPa}$ and $43 \mathrm{MPa}$ at $723 \mathrm{~K}$ and $773 \mathrm{~K}\left(450{ }^{\circ} \mathrm{C}\right.$ and $\left.500{ }^{\circ} \mathrm{C}\right)$, respectively. A good agreement between the experimental stress values with the ones calculated from the Orowan-Ashby model indicates that the dislocations bypass the precipitates through the Orowan-bowing mechanism in regime III and also, unlike in regime II, dislocations bypassing the precipitates using climb is not the rate-controlling mechanism in regime III. Additionally, the dislocations, which were still pinned by the precipitates in regime III, were observed to make a breaking angle $(\phi)$ - the angle between the two arms of the dislocations bowing around the precipitate as depicted in Figure 20-close to zero suggesting that the precipitates might act as impenetrable obstacles. As a result, it is likely that the dislocation arms might pinch off to cross the precipitates through the Orowan-bowing mechanism. ${ }^{[25]}$

\section{E. Creep Threshold Stress}

A distinct feature that has been noted in the creep behavior of several precipitation-hardened and dispersion-hardened materials is the existence of a threshold stress at the low stress levels, below which the creep rate would drop at an increasing rate to a negligible value. The origin of such a threshold stress can be related to 


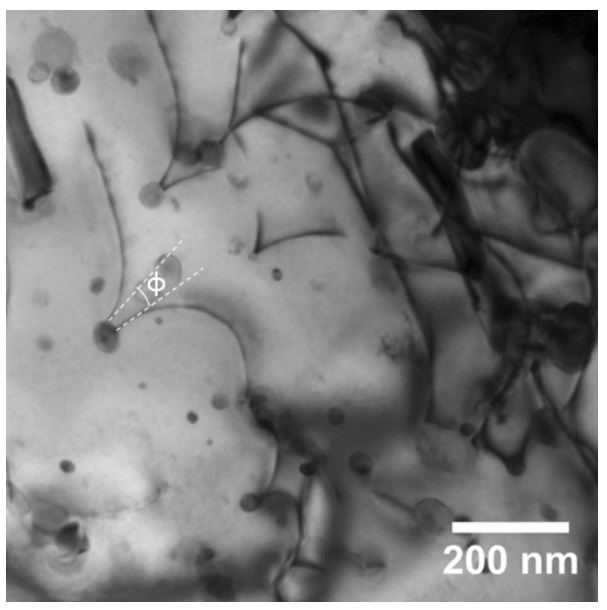

Fig. 20-TEM micrograph of the crept specimen at $99 \mathrm{MPa}$ and $723 \mathrm{~K}\left(450{ }^{\circ} \mathrm{C}\right)$ in regime III $(n=4.5)$ showing dislocations pinned by the precipitates. As seen, the breaking angle $(\varphi)$ is close to zero for all dislocations suggesting that they might bypass the precipitates through the Orowan mechanism.

any of particle shearing, dislocation climb-controlled bypass, or dislocation-particle detachment. ${ }^{[45]}$ According to the model by Rösler and Arzt, ${ }^{[46]}$ which was derived for the general climb of dislocations over precipitates, an expression for the creep threshold stress $\left(\sigma_{\mathrm{th}}\right)$ was obtained in the form of,

$$
\frac{\sigma_{\mathrm{th}}}{\sigma_{\mathrm{O}-\mathrm{A}}}=\frac{\langle r\rangle}{2 \lambda} .
$$

The origin of the threshold stress was attributed to the stress required for a small increment in the length of the dislocation line while climbing, which is necessary to keep up a minimum energy configuration. This relation given in Eq. [15] could be applied to HANA-4 since general climb of dislocations has been suggested to occur in regime II. Accordingly, the threshold stress for HANA-4 calculated using Eq. [15] is about $4 \mathrm{MPa}$ in all the test temperatures employed in this study if the very small difference in the stress values arising due to the variance in temperatures is neglected. However, as seen from the creep data of HANA-4 at $773 \mathrm{~K}\left(500^{\circ} \mathrm{C}\right)$, the creep rates in regime II transit into regime I, where diffusional creep mechanism was suggested to be operative, at a stress of $19 \mathrm{MPa}$. It can thus be argued that the threshold stress arising from the general climb process in regime II would not be revealed in the case of HANA-4. Alternately, Coble creep has become the rate-controlling step at low stresses as shown by the model predictions. This can be justified by considering the fact that general climb and Coble creep mechanisms proceed in parallel and that the faster mechanism would dictate the creep rate. Thus, Coble creep proceeds at a faster rate than the dislocationbased mechanism below the applied stress of $19 \mathrm{MPa}$.

\section{CONCLUSIONS}

The creep behavior of newly developed HANA-4 (Zr1.5 pct alloy) cladding has been investigated with a focus on identifying the transitions in creep mechanisms. Biaxial creep tests on HANA-4 tubes were conducted using internal pressurization of closed-end tubes to gather the steady-state creep data over a range of hoop stresses, $8.38 \times 10^{-5} E-2.87 \times 10^{-3} E$, at three different temperatures $673 \mathrm{~K}, 723 \mathrm{~K}$, and $773 \mathrm{~K}\left(400{ }^{\circ} \mathrm{C}, 450{ }^{\circ} \mathrm{C}\right.$ and $500{ }^{\circ} \mathrm{C}$ ). The mechanistic creep parameters such as stress exponent $(n)$ and activation energy $\left(Q_{\mathrm{C}}\right)$ were then determined from steady-state creep rates. Based on the variance in stress exponent with respect to the applied stress, three regimes have been identified: a stress exponent close to 1 at low stresses increased to 3 at the intermediate stresses, which became 4.5 at high stresses. These regimes are referred to as I, II, and III, respectively. An activation energy value of $226 \mathrm{~kJ} / \mathrm{mol}$ was evaluated for regimes II and III, which lies close to that for self-diffusion $\left(Q_{\mathrm{L}}\right)$ in $\alpha-\mathrm{Zr}$ alloys. Further, TEM analyses of crept microstructures and comparison of experiments results with standard models were undertaken to find out the rate-controlling mechanisms. The following are the important observations from this study.

1. In regime 1 , Coble creep has been suggested as the dominant mechanism based upon the stress exponent close to 1 and the fine grain size in HANA-4. As well, a good correlation between the experimental rates in regime $I$ with the Coble creep model predictions substantiated the proposal.

2. At intermediate stresses, the crept microstructure revealed a uniform distribution of dislocations throughout grain interior pinned by the precipitates suggesting that dislocations bypassing precipitates is the slower process than the glide between precipitates. Further, $n=3$ and $Q_{\mathrm{C}}=Q_{\mathrm{L}}$ in regime II indicates dislocations climbing over the precipitates as the rate-controlling mechanism in accordance with the model by Rösler and Arzt. Thus, for the first time, we show that the creep behavior of a $\mathrm{Zr}$ $\mathrm{Nb}$ alloy is similar to that of certain precipitationhardened materials but not of a class-A alloy (viscous glide or microcreep).

3. With $n=4.5$ and $Q_{\mathrm{C}}=Q_{\mathrm{L}}$ in regime III that occurred at high stresses, recovery of dislocations through climb as characterized by the Weertman model is identified as the rate-controlling mechanism. A good prediction of the experimental creep rates by the Weertman model and the TEM analyses, which revealed sub-boundaries and networks formed by dislocations, support the proposed mechanism.

4. The critical stress of transition from regime II to regime III was found to be equivalent to that required for the activation of the Orowan bypass mechanism by which dislocations could bypass the precipitates without an involvement of the dislocation climb process.

5. A low creep threshold stress of $\sim 4 \mathrm{MPa}$ was estimated based on the general climb model of Rösler and Arzt at the test temperatures. However, the threshold stress possibly would not be revealed at the calculated stress owing to the dominance of 
Coble creep at these low stress levels $(<19 \mathrm{MPa})$ at $773 \mathrm{~K}\left(500^{\circ} \mathrm{C}\right)$.

\section{ACKNOWLEDGMENTS}

The authors acknowledge the use of the Analytical Instrumentation Facility (AIF) at North Carolina State University, which is supported by the State of North Carolina and the National Science Foundation. This research is supported by DOE-NEUP under the Integrated Research Project (IRP) entitled, 'Fuel Aging in Storage and Transportation (FAST), US National Science Foundation through grant DMR 0968825, and a grant from Korea Atomic Energy Research Institute (KAERI).

\section{REFERENCES}

1. K. Linga Murty and I. Charit: Prog. Nucl. Energy, 2006, vol. 48, pp. 325-59.

2. K.L. Murty and I. Charit: J. Nucl. Mater., 2008, vol. 383, pp. 189 95

3. I. Charit and K.L. Murty: J. Nucl. Mater., 2008, vol. 374, pp. 354 63.

4. K.L. Murty: Trans. Indian Inst. Met., 2000, vol. 53, pp. 107-20.

5. H.-G. Kim, I.-H. Kim, B.-K. Choi, J.-Y. Park, Y.-H. Jeong, and K.-T. Kim: Corros. Sci., 2010, vol. 52, pp. 3162-67.

6. Y.I. Jung, M.H. Lee, H.G. Kim, J.Y. Park, and Y.H. Jeong: $J$. Alloy. Compd., 2009, vol. 479, pp. 423-26.

7. Y.H. Jeong, H.G. Kim, D.J. Kim, B.K. Choi, and J.H. Kim: $J$. Nucl. Mater., 2003, vol. 323, pp. 72-80.

8. Y.H. Jeong, K.O. Lee, and H.G. Kim: J. Nucl. Mate., 2002, vol. 302, pp. 9-19.

9. Y.H. Jeong, S.-Y. Park, M.-H. Lee, B.-K. Choi, J.-H. Baek, J.-Y. Park, J.-H. Kim, and H.-G. Kim: J. Nucl. Sci. Technol., 2006, vol. 43 , pp. $977-83$.

10. K.L. Murty: Jom-J Min Met Mat S, 2000, vol. 52, pp. 34-38.

11. K.L. Murty: Jom-J Min Met Mat S, 1999, vol. 51, pp. 32-39.

12. Y. Zhou, B. Devarajan, and K.L. Murty: Nucl. Eng. Des., 2004, vol. 228, pp. 3-13.

13. K.L. Murty, J. Ravi, and Wiratmo: Nucl. Eng. Des., 1995, vol. 156 , pp. $359-71$.

14. J.C. Britt, J. Ravi, Wiratmo, and K.L. Murty: Proceedings of the Sixth International Symposium on Environmental Degradation of Materials in Nuclear Power Systems-Water Reactors 1993, pp. 483-90.

15. W.R. Thorpe and I.O. Smith: J. Nucl. Mater., 1978, vol. 75, pp. 209-19.

16. A. Pahutová, J. Cadek, and V. Cerný: J Nucl Mater, 1976, vol. 61, pp. $285-96$.

17. M.I. Alymov, E.N. Pirogov, and L.L. Artyukhina: At. Energy, 1987, vol. 62, pp. 441-44.

18. K. Linga Murty, J. Ravi, and Wiratmo: Nucl. Eng. Des., 1995, vol. 156, pp. $359-71$.

19. J. Ravi and K.L. Murty: in Johannes Weertman Symposium: TMS Annual Meeting, R.J. Arsenault, D. Cole, H. Sizek, P. Liaw, G. Parameswaran, and G. Kostorz, eds., The Society, Anaheim, California, 1996, pp. 203-09.

20. K.L. Murty: Scr. Metall., 1973, vol. 7, pp. 899-903.

21. T.A. Hayes and M.E. Kassner: Metall. Mater. Trans. A, 2006, vol. 37A, pp. 2389-96.

22. T.A. Hayes, M.E. Kassner, and R.S. Rosen: Metall. Mater. Trans. A, 2002, vol. 33A, pp. 337-43.

23. J. Weertman: Trans. ASM, 1968, vol. 61, pp. 680-94.
24. E. Orowan: Symposium on Internal Stresses in Metals and Alloys, London, 1948, p 451.

25. J.W. Martin: Precipitation Hardening, Butterworth-Heinemann, Oxford, 1998.

26. S. Gollapudi, I. Charit, and K.L. Murty: Acta Mater., 2008, vol. 56, pp. 2406-19.

27. I. Charit and K.L. Murty: Mater. Sci. Forum., 2007, vols. 539-543, pp. $3377-82$.

28. H. Okamoto: J. Phase Equilib., 1992, vol. 13, p. 577.

29. R. Jerlerud Pérez and A.R. Massih: J. Nucl. Mater., 2007, vol. 360, pp. $242-54$.

30. A. Guillermet: Zeitschrift fur Metailkunde, 1991, vol. 82, pp. 47887.

31. H.E. Rosinger and D.O. Northwood: J. Nucl. Mater., 1979, vol. 79, pp. 170-79.

32. V.S. Lyashenko, V.N. Bykon, and L.V. Pavlinov: Fiz. Metal. Metalloved, 1959, vol. 8, pp. 362-69.

33. R.L. Coble: J. Appl. Phys., 1963, vol. 34, pp. 1679-82.

34. J. Harper and J.E. Dorn: Acta Metall., 1957, vol. 5, pp. 654-65.

35. Conyers. Herring: J. Appl. Phys., 1950, vol. 21, pp. 437-45.

36. F.R.N. Nabarro: The Physical Society, London, 1948.

37. K.L. Murty: Mater. Sci. Eng., 1974, vol. 14, pp. 169-77.

38. J. Novotný, J. Fiala, and J. Cadek: Acta Metall., 1985, vol. 33, pp. 905-11.

39. B. Kombaiah and K. Linga Murty: Philos. Mag., 2015, vol. 95, pp. 1656-79.

40. K. Vieregge, R. Willecke, and C. Herzig: Le Journal de Physique Colloques, 1990, vol. 51, pp. C1-691-96.

41. J.E. Bird, A.K. Mukherjee, and J.E. Dorn: in Quantitative relation between properties and microstructure, D.G. Brandon and A. Rosen, eds. Israel University Pressm, Haifa, Israel, 1969, pp 255-342.

42. K. Linga Murty: Mater. Sci. Eng., 1974, vol. 14, pp. 169-77.

43. J. Weertman: J. Appl. Phys., 1957, vol. 28, pp. 1185-89.

44. N.Q. Vo, C.H. Liebscher, M.J.S. Rawlings, M. Asta, and D.C. Dunand: Acta Mater., 2014, vol. 71, pp. 89-99.

45. E.A. Marquis and D.C. Dunand: Scripta Mater., 2002, vol. 47, pp. 503-08.

46. J. Rösler and E. Arzt: Acta Metall., 1988, vol. 36, pp. 1043-51.

47. E. Arzt and J. Rösler: Acta Metall., 1988, vol. 36, pp. 1053-60.

48. E. Arzt and M.F. Ashby: Scr. Metall., 1982, vol. 16, pp. 1285-90.

49. B.G. Clark, I.M. Robertson, L.M. Dougherty, D.C. Ahn, and P. Sofronis: J. Mater. Res., 2005, vol. 20, pp. 1792-1801.

50. A. Melander and P.A. Persson: Acta Metall., 1978, vol. 26, pp. 267-78.

51. R. Lagneborg and B. Bergman: Metal. Sci., 1976, vol. 10, pp. 20-28.

52. J. Cadek: Creep in Metallic Materials, Elsevier Science Publishers B. V, Amsterdam, The Netharlands, 1988.

53. R.W. Weeks, S.R. Pati, M.F. Ashby, and P. Barrand: Acta Metall., 1969, vol. 17, pp. 1403-10.

54. B.M. Morrow, R.W. Kozar, K.R. Anderson, and M.J. Mills: Acta Mater., 2013, vol. 61, pp. 4452-60.

55. G.B. Viswanathan, V.K. Vasudevan, and M.J. Mills: Acta Mater., 1999, vol. 47, pp. 1399-1411.

56. F.R.N. Nabarro: Mater. Sci. Eng. A, 2004, vols. 387-389, pp. 65964.

57. J. Weertman: J. Appl. Phys., 1957, vol. 28, pp. 362-64.

58. J. Weertman: in Rate Processes in Plastic Deformation of Materials, A.K. Mukherjee and J.C.M. Li, eds, ASM, Cleveland, Ohio, 1972, pp. 315-336.

59. J. Weertman: Trans. Metal. Soc. Aime, 1960, vol. 218, p. 207.

60. B. Jansson and A. Melander: Scr. Metal., 1978, vol. 12, pp. 49798.

61. P.G. Shewmon: Transformations in Metals, McGraw-Hill, New York, 1969, p. 312.

62. M. Ivermark, J. Robson, M. Preuss, and S.W. Dean: J. ASTM Int., 2010, vol. 7, p. 103011.

63. J.D. Robson: J. Nucl. Mater., 2008, vol. 377, pp. 415-22.

64. E. Nembach: Phys. Status Solidi (a), 1983, vol. 78, pp. 571-81.

65. J. Goldak, L.T. Lloyd, and C.S. Barrett: Phys. Rev., 1966, vol. 144, pp. $478-84$.

66. Y.F. Bychkov, A.N. Rozanov, and D.M. Skorov: Sov. J. At. Energy, 1957, vol. 2, pp. 171-75. 